\title{
Assessing precipitation seasonal forecasts in Central Africa using North American Multimodel Ensemble (NMME)
}

Armand Tchinda Feudjio ( $\square$ armand.tchinda@imsp-uac.org )

UAC IMSP: Universite d'Abomey-Calavi Institut de Mathematiques et de Sciences Physiques

https://orcid.org/0000-0003-0517-9495

Roméo Stève TANESSONG

Ossénatou MAMADOU

Jean Bio CHABI OROU

\section{Research Article}

Keywords: NMME, lead time, MME, Seasonal forecasts, Central Africa

Posted Date: March 17th, 2021

DOI: https://doi.org/10.21203/rs.3.rs-278585/v1

License: (c) (i) This work is licensed under a Creative Commons Attribution 4.0 International License.

Read Full License 


\title{
Assessing precipitation seasonal forecasts in Central Africa using North American Multimodel Ensemble (NMME)
}

\author{
Armand Tchinda Feudjio ${ }^{1,}$, Roméo Stève Tanessong ${ }^{2}$, Ossénatou Mamadou ${ }^{3}$, Jean Bio \\ Chabi Orou ${ }^{4}$
}

Received: date / Accepted: date

\author{
${ }^{1}$ Institute of Mathematics and Physical Sciences (IMPS-UAC) BP: 613 Avakpa, Porto-Novo, Benin \\ ${ }^{2}$ University of Dschang-Cameroon, Faculty of Agronomy and Agricultural Sciences School of W ood, \\ water and Natural Resources, PO Box 786, Ebolowa (Cameroon) \\ ${ }^{3}$ Institute of Mathematics and Physical Sciences (IMPS-UAC) BP: 613 Avakpa, Porto-Novo, Benin. \\ Laboratoire de Physique du Rayonnement (LPR), Université d'Abomey Calavi \\ ${ }^{4}$ Institute of Mathematics and Physical Sciences (IMPS-UAC) BP: 613 Avakpa, Porto-Novo, Benin. \\ Laboratoire de Mécanique de Fluides et des Systèmes Dynamiques.
}

\section{"Corresponding author: Tchinda Feudjio Armand}

*Corresponding author address: armand.tchinda@imsp-uac.org

\begin{abstract}
This study examines the seasonal forecast of the North American Multi-Model Ensemble (NMME) over Central Africa (CA), which encompasses a region of the world where the economies of the countries are heavily dependent on agriculture and livestock. The forecast evaluation is done over the 4 seasons: December to February (DJF), March to May (MAM), June to August (JJA), September to November (SON) between 0 to 5 months lead time before the beginning of each season corresponding to many regional climate perspectives. Deterministic and categorical approaches focusing on the rainfall variable were used to assess NMME models over CA. The observed and predicted rainfall have been divided into three categories: below normal, normal and above normal. The results show that for 0 to 2 months lead time, the NMME Multi-model Ensemble Mean (MME)
\end{abstract}


reproduces rainfall peaks ( 9 to $10 \mathrm{~mm} /$ days) at the level of Atlantic coast and in East of Democratic Republic of Congo in MAM and SON. Always between 0 to 2 months lead time, values of correlation coefficients $(\mathrm{R})$ of all seasons are greater than 0.72 . For 3 to 5 months lead time, low values of $\mathrm{R}$ are observed. It follows that probabilities of detection (POD) are greater than $50 \backslash \%$ for all different normal seasons and less than $45 \backslash \%$ for below and above normal seasons. On the other hand, high false alarm (FAR) values and low Critical Success Index (CSI) values are observed for both below and above normal seasons. The NMME model emerges as an interesting tool capable of providing important seasonal characteristics up to several months ( 5 months) before the start of the season in the CA, which will allow proper consideration of meteorological phenomena.

Keywords NMME lead time MME Seasonal forecasts Central Africa

\section{Introduction}

Central Africa (CA) is one of the regions of the world where rainfall is very complex and varies on several scales (Jenkins et al 2005). In this region, agriculture is practiced in many countries; productivity is highly dependent on the availability of water resources, which are controlled by the distribution and amount of rain. The verification of water resources in CA nowadays has become essential because the economy of the countries of this region depends on agriculture and livestock ( Roncoli et al 2012 ). This populated region with over 500 million people is very sensitive to climatic variations that can affect the population (Fotso-Nguemo et al 2017).

In this context, forecasts can be emitted at different time scales depending on the user's needs. Seasonal forecasts permit to study whether months or seasons will be warmer or colder, drier or wetter than normal. Seasonal forecasts can be useful in many areas. For example, seasonal forecasts can be used to quantify the availability of water resources and to adapt agricultural practices, particularly in Western and Central Africa (Sultan et al 2003). After more than three decades of research on origins of seasonal climate, progress is being observed around the world today (Wu et al 2003; DeWitt 2005). This progress is due to multiple approaches, international and multi-institutional collaborations and finally efforts between researchers. Techniques of quantitative information regarding uncertainty in forecasts were observed (Mason et al 2001; Hagedorn et al 2005; Yuan et al 2011). The other approach is to recognize multi-model strategies used to determine uncertainty that may exist in forecasts (Wang et al 2005; Palmer et al 2008). NMME have been developed to provide information on the problems of climate variability and especially to improve quality of seasonal forecasts around the world (Kirtman et al 2014; Thober et al 2015; Slater et al 2017; Shukla et al 2016). 
Several recent studies have inspected the skill of NMME. Mo et al (2015) assessed the skill of NMME using Standardized Precipitation Indices (SPIs) in global land areas. They established that skills of SPI forecasts engendered by NMME depend on the season, location and specific index ( 3 and 6 month SPI were assessed). They also showed that in almost all locations and seasons, statistically significant skills are found within 1 to 2 months. Slater et al (2017) studied the skill of eight NMME in seven regions of the United States. They found that most predicted skills occur at the shortest lead time and may decline thereafter. Shukla et al (2016) assessed the skill of NMME seasonal forecasts in East Africa (EA), using deterministic, categorical, and probabilistic assessment methods for three main seasons, March to May (MAM), July to September (JAS) and October to December (OND). They found that rainfall forecasts in this region are generally limited and are statistically significant only over a very small part of the domain.

Seasonal forecasting using NMME has not received much attention in Central Africa. The above study on NMME project will be very useful in CA where agriculture is mainly rain-fed and is extremely sensitive to climatic fluctuations. This study assesses the seasonal forecast from NMME. The evaluation is done over 4 seasons: December to February (DJF), March to May (MAM), June to August (JJA) and September to November (SON) between 0 to 5 months lead time before beginning of each season in CA. The paper is structured as follows: Section 2 presents NMME data and methodology. Section 3 focuses on the main results and discussion. The conclusion is presented in section 4.

\section{Data and methodology}

\subsection{Description of the study area}

The study area is shown in Figure 1 and is defined by the latitude $-10^{\circ}$ to $16^{\circ}$ and longitudes $5^{\circ}$ to $33^{\circ}$ $\mathrm{CA}$ is surrounded by and divided into mountains and plateaux, namely the Joss Plateau (Nigeria), the Mandara Mountains and the Adamaoua Plateau (northern Cameroon), and the highlands of western Cameroon, Mount Cameroon (southwestern Cameroon), the Yadé Massif (western Central African Republic), the Cristal Mountains (between southern Equatorial Guinea and northwestern Gabon), the Batéké Plateau (southern Congo). These plateaux and mountains influence rainfall in the region and climate is becoming very complex and represents a considerable challenge to climatic models (Vondou et al 2010; Fotso-Nguemo et al 2018). 


\section{Central Africa Topography}

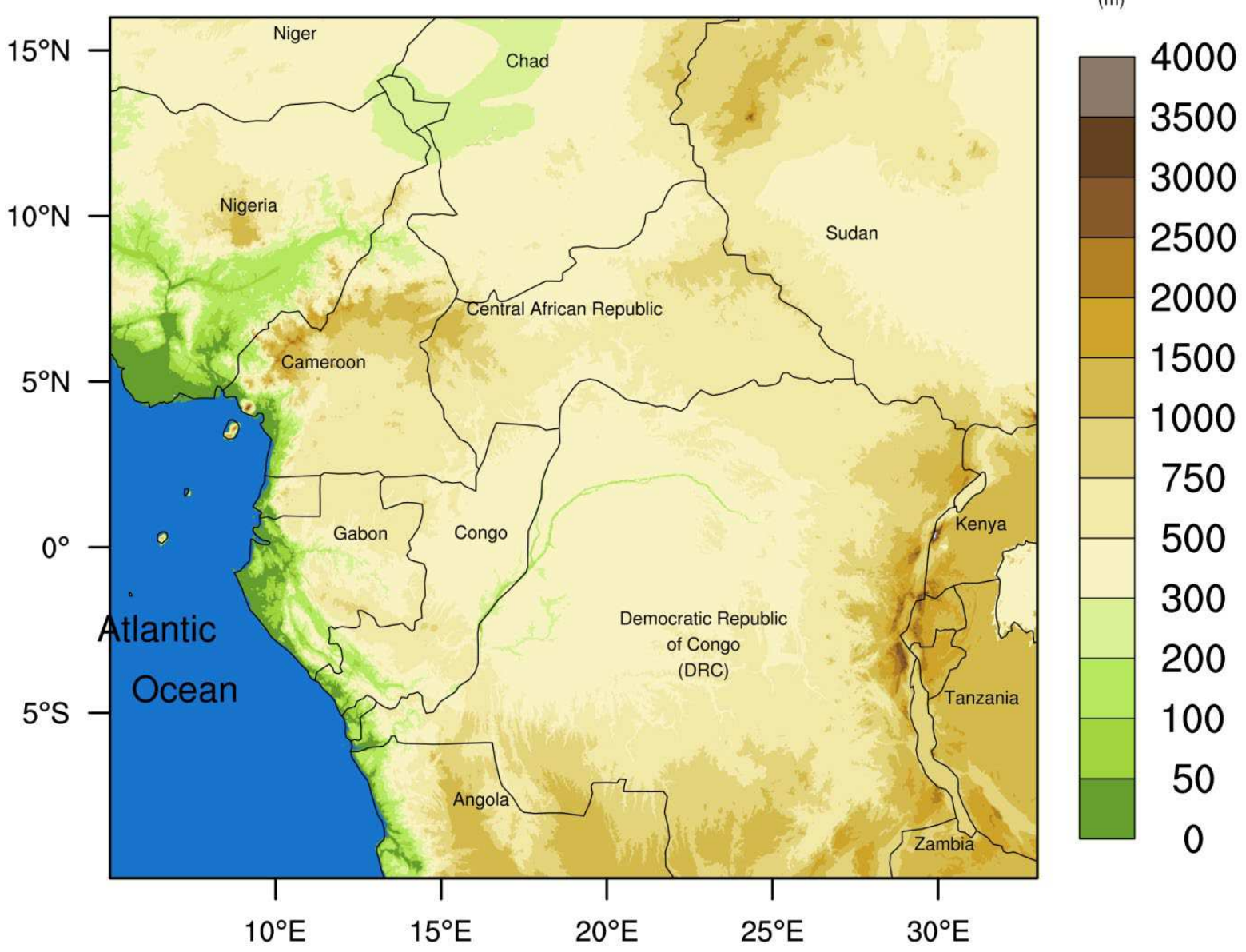

Fig. 1 Study area located between the latitudes $-10^{\circ}$ to $16^{\circ}$ and longitudes $5^{\circ}$ to $33^{\circ}$

\subsection{NMME data}

NMME hindcasts are obtained from Columbia University's International Research Institute (IRI) data library (https://iridl.ldeo.columbia.edu/SOURCES/ $\$.Models/.NMME /). NMME data are monthly with horizontal resolution of $1^{\circ} \times 1^{\circ}$ longitude/latitude. NMME combines several fully coupled climatic models to provide real climate forecast systems for a period of more than 8 months. in advance (some models produce forecasts up to about 11 months in advance). The description of the different models is summarized in Table 1 (Kirtman et al 2014). The data contain 5 dimensions (Lon, Lat, M, L, S) namely the Longitude (Lon), Latitude (Lat), Member (M), Lead time (L) and initialization time $(\mathrm{S})$. The term lead time indicates the period between the forecast initialization time and the forecast month. In this paper, the NMME are evaluated relative to two observations data. 
Table 1 List of NMME outputs, and their configurations to use in this paper

\begin{tabular}{|c|c|c|c|c|c|}
\hline Models & hincast period & lead time (months) & Ensemble size & $\begin{array}{l}\text { Institute and model } \\
\text { version }\end{array}$ & References \\
\hline CFSV2 & $1982-2010$ & $0.5-9.5$ & 24 & NCEP coupled model & Saha et al. (2014) \\
\hline CFSV1 & $1981-2009$ & $0.5-8.5$ & 15 & NCEP coupled model & Saha et al. (2006) \\
\hline NCAR-CESM1 & 1980-2011 & $0.5-11.5$ & 10 & $\begin{array}{l}\text { NCAR coupled earth } \\
\text { system model }\end{array}$ & Gent et al. (2010) \\
\hline $\begin{array}{l}\text { COLA-RSMAS- } \\
\text { CCSM3 }\end{array}$ & $1982-2010$ & $0.5-11.5$ & 6 & $\begin{array}{l}\text { COLA/University of } \\
\text { Miami/NCAR coupled } \\
\text { model }\end{array}$ & Collins et al. (2006) \\
\hline $\begin{array}{l}\text { COLA-RSMAS- } \\
\text { CCSM4 }\end{array}$ & $1982-2010$ & $0.5-11.5$ & 10 & $\begin{array}{l}\text { COLA/University of } \\
\text { Miami/NCAR coupled } \\
\text { model }\end{array}$ & Collins et al. (2006) \\
\hline $\begin{array}{l}\text { GFDL-CM2p5-FLOR- } \\
\text { A06 }\end{array}$ & $1982-2010$ & $0.5-11.5$ & 10 & $\begin{array}{l}\text { Expanded version of } \\
\text { GFDL of } \\
\text { Miami/coupled model, } \\
\text { FLOR-A06 }\end{array}$ & Zhang et al. (2007) \\
\hline $\begin{array}{l}\text { GFDL-CM2p5-FLOR- } \\
\text { B01 }\end{array}$ & $1982-2010$ & $0.5-11.5$ & 10 & $\begin{array}{l}\text { Expanded version of } \\
\text { GFDL of } \\
\text { Miami/coupled model, } \\
\text { FLOR-A06 }\end{array}$ & Zhang et al. (2007) \\
\hline $\begin{array}{l}\text { IRI-Echam4p5- } \\
\text { anomaly coupled }\end{array}$ & $1982-2010$ & $0.5-11.5$ & 12.5 & $\begin{array}{l}\text { IRI, anomaly coupled } \\
\text { model -anomaly } \\
\text { coupled }\end{array}$ & DeWitt (2005) \\
\hline CanCM3 & $1981-2010$ & $0.5-11.5$ & 10 & $\begin{array}{l}\text { 3rd generation } \\
\text { Canadien coupled } \\
\text { global climate model }\end{array}$ & $\begin{array}{l}\text { Merryfield et al. } \\
\text { (2013) }\end{array}$ \\
\hline CanCM4 & 1981-2009 & $0.5-11.5$ & 10 & $\begin{array}{l}\text { Canadien coupled } \\
\text { global climate model }\end{array}$ & $\begin{array}{l}\text { Merryfield et al. } \\
\text { (2013) }\end{array}$ \\
\hline GEM NEMO & $1981-2010$ & $0.5-11.5$ & 10 & $\begin{array}{l}\text { Canadian } \\
\text { Meteorological Centre }\end{array}$ & Kirtman et al. (2014) \\
\hline
\end{tabular}

\subsection{Observation datasets}

To verify and evaluate the NMME models, in order to reproduce the main characteristics of the CA climate, data from the Global Precipitation Climatology Center (GPCC) (Becker et al 2013; Schneider et al 2011; Adler et al 2016) and the NMME-CPC-CMAP PRATE observations data (Zhao et al 2019) are used. Their respective spatial resolutions are $0.5^{\circ} \times 0.5^{\circ}$ and $1^{\circ} \times 1^{\circ}$. The GPCC and NMME-CPCCMAP PRATE are satellite observation data and they contain 3 dimensions (longitude, latitude and time). 
The two observations are downloaded over the same period 1982-2009. The NMME-CPC and GPCC data sets are all remeshed to $1^{\circ} \times 1^{\circ}$ to match the NMME models grids. This data preprocessing facilitates comparison results for different forecast sets (Kirtman et al 2014; Liu et al 2017).

\subsection{Methodology}

\subsubsection{Forecast evaluation metrics}

The skill of NMME is evaluated using retrospective forecasts of 11 dynamic models for the period 1982-2009. MME was examined by first designing ensemble means of every individual model for each season and then averaging the ensemble means of all models as in Shukla et al (2016) and Tanessong et al (2020). The strengths of this method lie in a procedure for optimizing deterministic forecast and evaluating uncertainty due to model imperfections. Various models, although very different in their parameters, can give rise to equivalent overall skill (Marchandise 2007; Kug et al 2008; Zhang et al 2018).

- In the first part of this evaluation, the climatologies of two observations (GPCC and NMME CPC PRATE) were calculated, and then a difference between the 2 climatologies was calculated in order to measure the uncertainty that may exist between these data observations. In addition, the climatology of the MME for each season DJF, MAM, JJA and SON, between 0 to 5 months in advance is represented in order to make comparison with the observations.

- The correlation coefficient $(\mathrm{R})$ is widely used and allows to highlight a linear link between forecast and observation. The $\mathrm{R}$ is given by equation (1) below, or the expressions of the parameters $\sigma_{p}, \sigma_{K}$, $\bar{P}$ et $\bar{K}$ are given by the equations (2), (3), (4) et (5) respectively. In equations (2), (3), (4), (5) and (6), $P_{j}$ indicates the predicted value, while $K_{j}$ indicates the observed value. $\mathrm{N}$ is the total number of grid points in the domain. The calculation of standard deviation $(\sigma)$ provides the measure of dispersion of the different MME. $\mathrm{R}$ and $\sigma$ are summarized in the Taylor diagram which permits a better measurement of the degree of similarities and differences between the MME and a reference observation GPCC (Taylor et al 2001).

$$
R=\frac{\frac{1}{N} \sum_{j=1}^{N}\left(P_{j}-\bar{P}\right)\left(K_{j}-\bar{K}\right)}{\sigma_{p} \sigma_{K}},
$$

Where $\sigma_{p}$ and $\sigma_{k}$ are the standard deviations of the predicted value $\mathrm{p}$ of the model and the observation value $\mathrm{k}$ defined respectively as: 


$$
\begin{aligned}
& \sigma_{P}=\left[\frac{1}{N} \sum_{j=1}^{N}\left(P_{j}-\bar{P}\right)\right]^{1 / 2} \\
& \sigma_{K}=\left[\frac{1}{N} \sum_{j=1}^{N}\left(K_{j}-\bar{K}\right)\right]^{1 / 2}
\end{aligned}
$$

The mean values $\bar{K}$ and $\bar{P}$ are respectively given by:

$$
\begin{aligned}
& \bar{P}=\frac{1}{N} \sum_{j=1}^{N} P_{j} \\
& \bar{K}=\frac{1}{N} \sum_{j=1}^{N} K_{j}
\end{aligned}
$$

- The Root Mean Square Error (RMSE), that is to say, equation (6) is normalized in this study by the climatological mean of the two observations and is given by equation (7). It facilitates the comparison between the forecast and the observation of each season.

$$
\begin{aligned}
& \operatorname{RMSE}=\left[\frac{1}{N} \sum\left(P_{j}-K_{j}\right)^{2}\right]^{1 / 2} \\
& N R M S E=\frac{R M S E}{\bar{K}}
\end{aligned}
$$

- The Mean Absolute Error (MAE) is given by equation (8). MAE is the absolute difference between the forecast value and that of the observation of each season in CA.

$$
M A E=\frac{1}{N} \sum_{j=1}^{N}\left|P_{j}-K_{j}\right|
$$

\subsubsection{Categorical skill scores}

In the context of seasonal forecasts, it is not realistic to believe that one can know the exact value of the amount of rain that will actually fall in an area. However, it is likely to know if the season will be dry or wet than a normal season through an assessment of the skills of the MME. The tertile categories: above normal (rainy), below normal (dried) and normal are used as in (Tippett et al 2007). The contingency table (Table 2) is used. Rainfall during a season is classified as below normal when anomalies are less than $-0.43 \sigma$, normal when the anomalies are between $-0.43 \sigma$ and $0.43 \sigma$ and above 
normal when the anomalies are greater than $0.43 \sigma$ (Stanski et al 1989; Shrivastava et al 2019). $\sigma$ represents the value of standard deviation for each grid point and for each season. The seasonal rainfall anomaly of different seasons JJA, MAM, DJF and SON is a difference between total seasonal rainfall and climatology. The climatology is an average of the seasonal rainfall for the period 1982 to 2009. The contingency table (Table 2), allows the calculation of the following meteorological parameters (Hamatan et al 2004).

Tableau 2 Contingence table for the calculation of forecast meteorological parameters between the observation GPCC and NMME

\begin{tabular}{|c|c|c|c|c|c|}
\hline & \multicolumn{3}{|c|}{ Forecast } & \multirow[b]{2}{*}{ Total } \\
\hline & & Rainy & Normal & Dried & \\
\hline \multirow[t]{4}{*}{ Observation } & Rainy & M11 & M12 & M13 & $\sum_{j=1}^{3} M 1 j$ \\
\hline & Normal & M21 & M22 & M23 & $\sum_{j=1}^{3} M 2 j$ \\
\hline & Dried & M31 & M32 & M33 & $\sum_{j=1}^{3} M 3 j$ \\
\hline & Total & $\sum_{i=1}^{3} M i 1$ & $\sum_{i=1}^{3} M i 2$ & $\sum_{i=1}^{3} M i 3$ & $\mathrm{M}$ \\
\hline
\end{tabular}

- Probability Of Detection (POD): is the ratio of observed "yes" events in each category that were exactly predicted. It varies from 0 to $1(100 \backslash \%)$ with a perfect number $1(100 \backslash \%)$.

$\operatorname{POD}($ Rainy $)=\frac{M 11}{\sum_{j=1}^{3} M 1 j} ; \quad$ POD $($ Dried $)=\frac{M 33}{\Sigma_{j=1}^{3} M 3 j} ; \quad$ POD $($ Normal $)=\frac{M 22}{\sum_{j=1}^{3} M 2 j} ;$

- False Alarm (FAR): event forecast to occur, but did not occur in each category. The score varies from 0 to $1(100 \backslash \%)$ with a perfect score of 0 .

FAR $($ Dried $)=\frac{M 13+M 23}{\sum_{i=1}^{3} M i 3} ; \quad$ FAR $($ Rainy $)=\frac{M 21+M 31}{\sum_{i=1}^{3} M i 1} ; \quad$ FAR $($ Normal $)=\frac{M 12+M 32}{\sum_{i=1}^{3} M i 2} ;$

- Critical Success Index (CSI): is a verification measure of categorical forecast performance which allows calculating the relative precision of each season. For the 3 categories it is given by:

CSI $($ Dried $)=\frac{M 33}{\sum_{i=1}^{3} M i 3+\sum_{j=1}^{3} M 3 j-M 33} ; \quad$ CSI (Rainy) $=\frac{M 11}{\sum_{i=1}^{3} M i 1+\sum_{j=1}^{3} M 1 j-M 11} ;$ 


$$
\mathrm{CSI}(\text { Normal })=\frac{M 22}{\sum_{i=1}^{3} M i 2+\sum_{j=1}^{3} M 2 j-M 22}
$$

It is ranged between 0 and 1 . The advantage that exists on the CSI over POD and FAR is that it is very sensitive to false alarms and missed events; thus, it gives a more representative idea of the real precision. It also allows to have more precision in situations where rare events are involved.

- Correct Percent (PC): it can be used to assess confidence in the forecasts for each season.

$$
\mathrm{PC}=100 \times \frac{\sum_{i=j=1}^{3} M i j}{M},
$$

Where $\mathrm{M}=28$ represents the period 1982-2009. Given that the study period is less than 30 years the threshold for being more meaningful is closer to $40 \backslash \%$ (Kharin et al 2009).

\section{Results and discussion}

This section presents and discusses the results of the MME forecasts by comparing them with the observations.

\subsection{MME and observation climatologies}

Figure 2 shows observations (GPCC and NMME CPC) climatologies (1982-2009) and difference between these observations. The first column shows DJF season, second column shows MAM, the third column shows the JJA and fourth column shows the SON season. The difference between climatologies of these observations (Fig. $2 \mathrm{~m}-\mathrm{p}$; fourth row) is used to measure uncertainty between these datasets. The result shows that GPCC is overestimated about $1.5 \mathrm{~mm} /$ day in the eastern part of the Democratic Republic of Congo (DRC) commonly referred to as the great lakes region in all the seasons (Fig. 2m-p), and at the level of the Atlantic coast in JJA and SON (Fig. 2o-p; fourth row). In addition, an underestimation of GPCC about $-2 \mathrm{~mm} /$ day is also observed in northwest Angola in the DJF and SON (see, Fig. $2 \mathrm{~m}$ and 2p), in part of southern Cameroon, northern Gabon and western DRC in JJA (Fig. 20). This underestimation and overestimation of the bias in the study area may be linked to the parametrization of the soil and geographic location (Dosio et al 2015; Tamoffo et al 2019). CA is largely forested and in addition, the region is surrounded by mountainous massifs and plateaus that can bias data, especially when derived from satellite sources (Fotso-Nguemo et al 2018). The 2 observations capture rainfall in the region at the continental level. The peaks of rainfall around 10 $\mathrm{mm}$ /days in the Gulf of Guinea and near Mount Cameroon in the southwestern part are clearly visible during the JJA and SON season (see, Fig. 2c-d, j-h and k-1). It follows that maximum (8 to 9 
$\mathrm{mm}$ /days) of rainfall is visible in the south Eastern part in DJF. This same maximum is observed in MAN season at the level, Congo Basin and Atlantic coast.
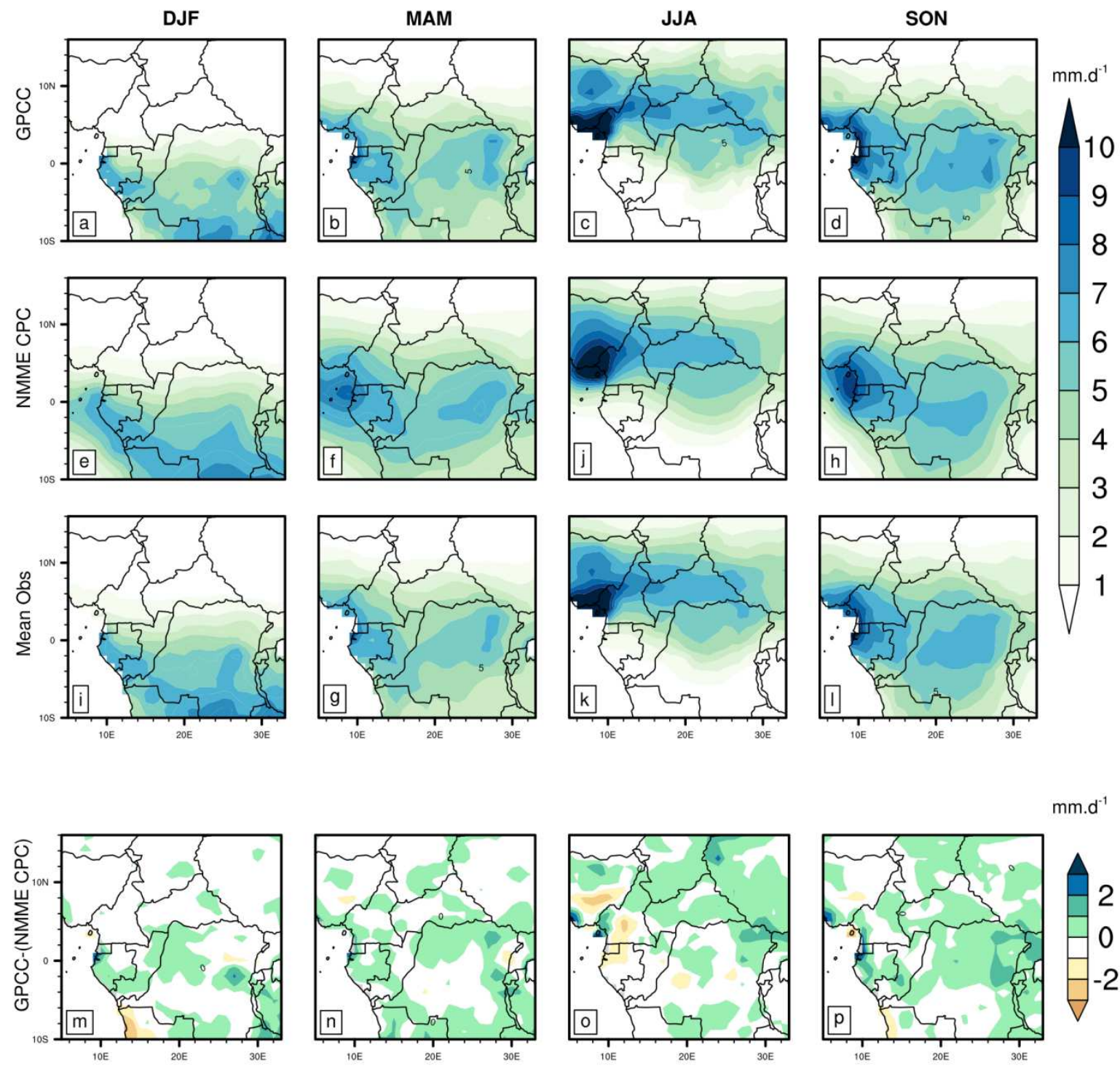

Fig. 2 Rainfall climatologies observed (1982-2009), a-d GPCC. e-h NMME CPC PRATE. i-1 means observation. m-p difference between GPCC and NMME CPC PRATE. For DJF column 1, MAM column 2, JJA column 3 and SON column 4

Figure 3 shows climatological MME of seasonal forecast between 0 to 5 months before the start of season. Columns 1, 2, 3, 4 represent season DJF, MAM, JJA and SON respectively. The results show that during the JJA season, MME captures precipitation in northern CA between 8 to $9 \mathrm{~mm} /$ days (Fig. 3c, j, k). MME presents a spatial distribution structure of precipitation at the lead 0 , lead 1 , and lead 2 almost similar to that of the observations. From lead 3 to lead 5 maxima are observable; however there is slight fluctuation rainfall observed towards the equatorial part of the region during 
this season (Fig. 3o, s, w). The fluctuation in precipitation from one area to another can be facilitated by convection, changes in surface flow Galvin et al (2008), by the presence of the Intertropical Convergence Zone (ITCZ) Nicholson and Grist (2003) and Jackson et al (2009), although Nicholson (2018) mentions that the precipitation peak does not depend solely on the ITCZ. However, one of great challenges of modeling rainfall in the sub-region is to present this observed seasonality. In general, during this season, lead 0 , lead 1 and lead 2 correctly reproduce rainfall with maximum rainfall centered near the Gulf of Guinea and Atlantic coast. The hypotheses illustrating these observed rainfall maxima can be related to the geographical position of the study area as well as differences in natural variability and surface water dynamics (Coppola et al 2014). CA is at the center of a continent crossed on both sides by the equator. Moreover this region is surrounded by several mountains and plateaus that can cause orographic rains due to forced convection of air masses (FotsoNguemo et al 2018). 

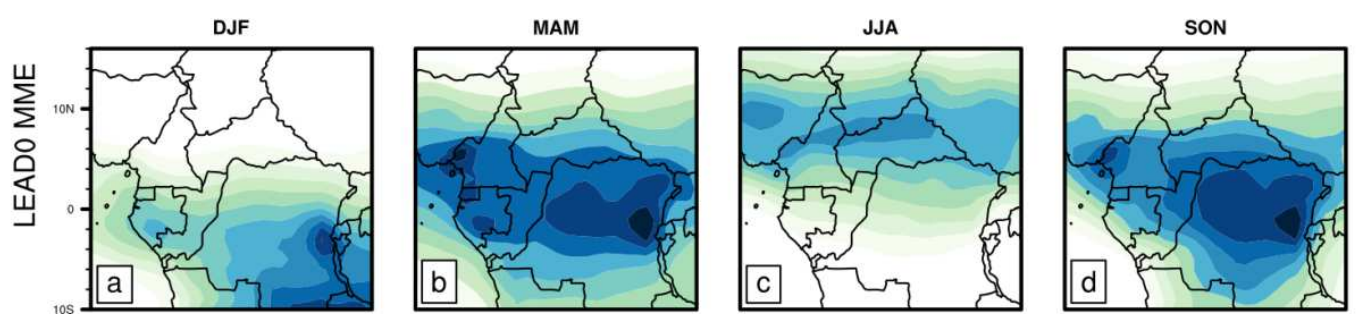

$m m \cdot d^{-1}$
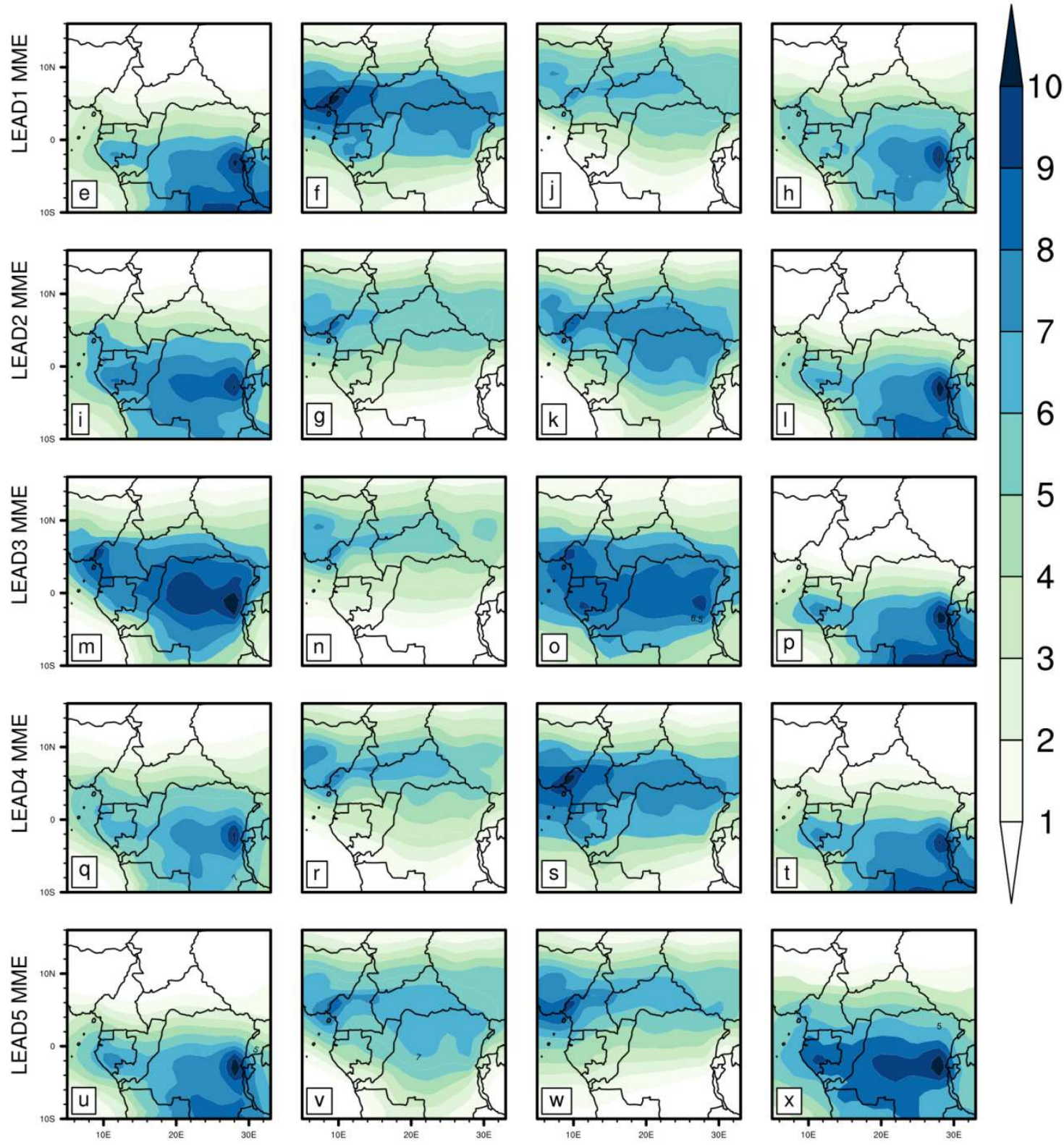

Figure 3 Seasonal forecast MME (1982-2009) rainfall (mm / day). DJF column 1, MAM column 2, JJA column 3 and SON column 4. 0 to 5 months lead time before the start of each season. a-d lead 0 . e-h lead 1. i-1 lead 2. m-p lead 3. q-t lead 4. u-x leads 5

During MAM and SON seasons 0-3 months lead time, MME rather shows that the equatorial region of CA is humid and presents a rainfall peak at the equator, around Congo Basin and East of DRC (Fig. $3 b, d, f$ and $h$ ). Rainfall peaks observed during these seasons at the equator follow the trend given by the two observations and can be explained by the existence of ITCZ and the presence of the Congo River. 
From 3 to 5 months lead time the SON season presents precipitation instead in the southern part of the region with the peaks at eastern DRC remaining observable (Fig. $3 \mathrm{p}, \mathrm{t}$ and $\mathrm{x}$ ). This result simply justifies that the quality of the forecast can deteriorate with the lead time.

During DJF, from lead 0 to lead 2, MME shows that the southern part of the region is wet while the northern part is dry (Fig. 3a, e and i). The two observations GPCC and the NMME CPC PRATE (Fig. 2a, e, i) similarly show the precipitation trend given by MME models. These results can be justified by the fact that monsoon characteristics such as the East African Jet (EAJ), the Tropical East Jet (TEJ) are inactive (Camberlin et al 2001; Nikulin 2012). It follows that the MME captures the spatial structure of precipitation well with a maximum at the level of Congo and the Democratic Republic of Congo around 7 to $8 \mathrm{~mm} /$ day (Fig. $3 \mathrm{~d}, \mathrm{~h}, 1)$. The extremes of rainfall obtained in this region can be caused by the proximity of the Congo River and also the great lakes region (Tanganyika lakes). During the same season, low rainfall is observed in the northern part of the region, in order of 1 to 3 $\mathrm{mm} /$ day. It should also be noted that rainfall varies slightly in the equatorial region when lead time increases (lead 3, lead 4 and lead 5) during this season. This proves deterioration in the quality of the forecast with the lead time. The MME models over 4 seasons favorably reflect the spatial structure of the rainfall 0-2 months lead time and represent the unimodal and bimodal nature of CA. These results are very consistent with what has been found in the literature review about the first months of forecasting Slater et al (2017), justifying the skill of the models at the first month of the forecast and with a decrease in performance when the lead time increases.

\subsection{Deterministic skill analysis}

The calculation of the different scores 0 to 5 months lead time before the beginning of the seasons between MME and observations are given in Figures 4, 5 and 6. Figure 4 indicates the bias between MME and the observation. The small black dots observed on these maps come from the significance tests performed on the calculated biases. They are consistent with the points where the disparity is 95\\% significant. A positive bias indicates an overestimation of MME rainfall compared to observations, while a negative bias indicates an underestimation. The results suggest that bias is drier from lead 0 to lead 1 for all seasons. For MAM and DJF seasons, the MME models underestimate the observations in northern CA and overestimate the observations in south with an observable maximum in northern Angola and DRC. In addition, for the JJA and SON seasons, the MME models overestimate the observations of the order of 2 to $3 \mathrm{~mm} /$ day in part of the southwestern region of Cameroon and part of Gulf of Guinea (Fig. 4c, d, j, h, k). These biases are more pronounced in the northern part of the $\mathrm{CA}$, around 4 to $5(\mathrm{~mm} / \mathrm{day})$, and a visible underestimation around -3 to -5 $(\mathrm{mm} /$ day) in the southern part of the CA, from lead 3 to lead 5 (Fig. 4o, p, s, t, w, x). In general, the result shows that the bias increases when the lead time deviates large. This fluctuation in bias can be 
Caused by the topography, as well as the soil parameters of the area (Coppola et al 2014). Another similar result was also found in East Africa by (Shukla et al 2016).
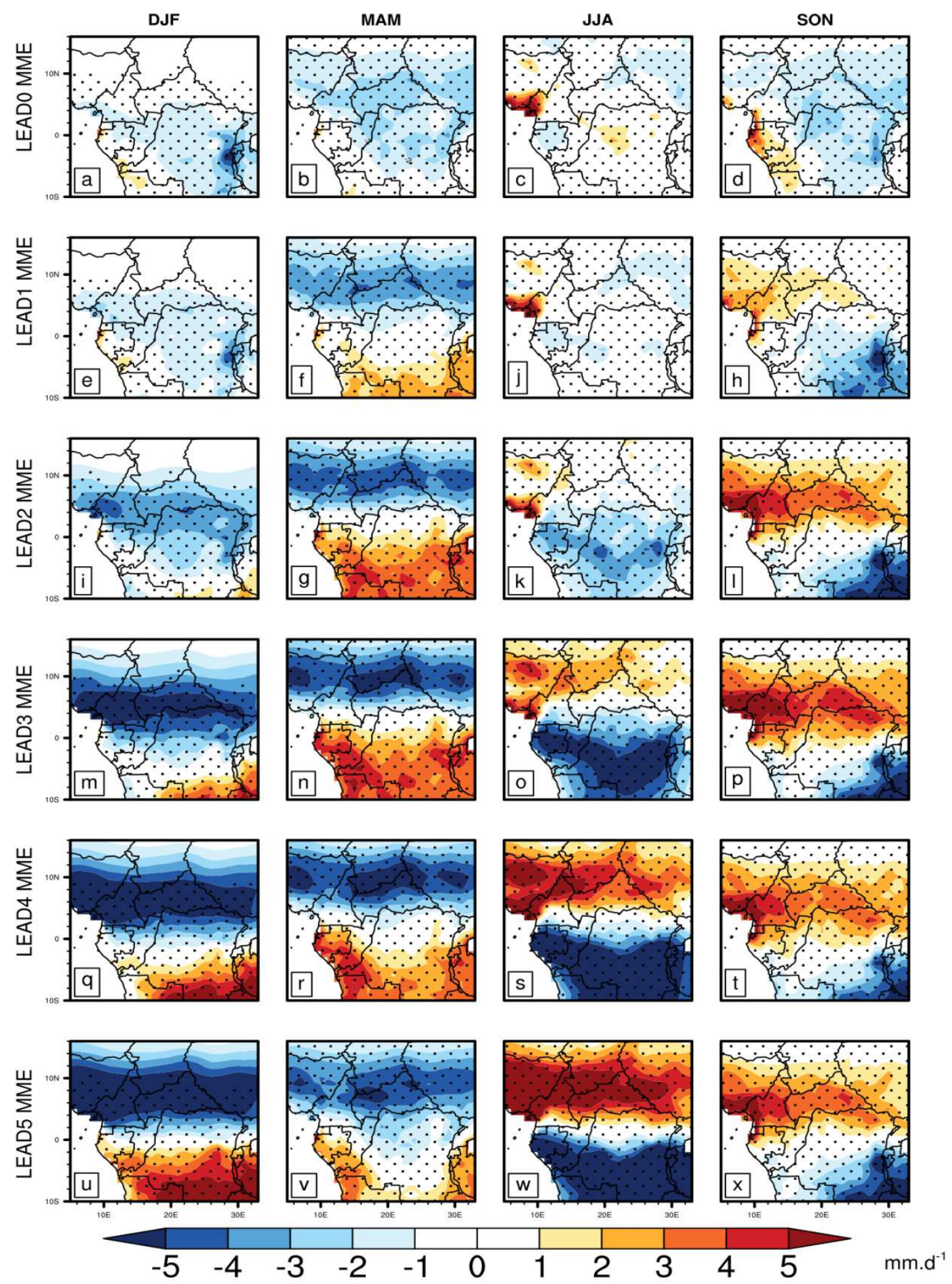

Fig. 4 Spatial distribution (1982-2009) MME bias. DJF column 1, MAM column 2, JJA column 3 and SON column 4.0 to 5 months lead time before the start of each season. a-d lead 0. e-h lead 1. i-1 lead 2. m-p lead 3. q$\mathrm{t}$ lead 4. u-x lead 5. The small black dots represent the significance test carried out at $95 \backslash \%$ 
In addition, Figure 5 shows an increasing dispersion with lead time. Both observations show the same trend for the 4 seasons studied with the median and the inter quartile of the boxplots which show an increasing trend with lead time. This may scientifically show a constraint to the increase of MME to maintain the quality of forecasts with the lead time. MAE and systematic bias, as shown in Figures 4 and 5 with the observations, indicate that there is a need to correct bias before applying NMME models in certain application domains, particularly for applications such as hydrological forecasts.

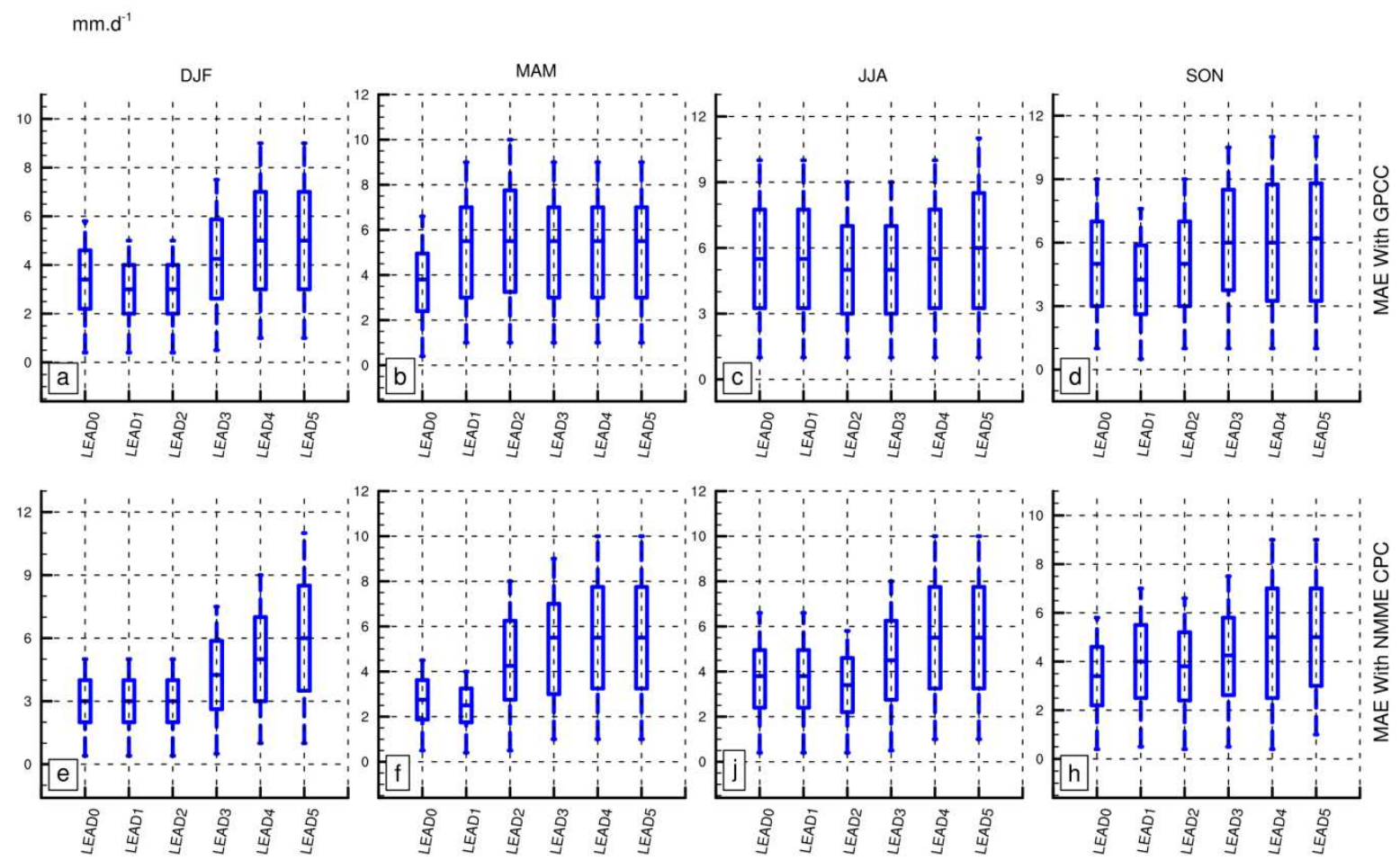

Fig.5 Box Plot representing the Mean Absolute Error (MAE) between the two observations GPCC and CPC NMME PRATE and the MME. For DJF, MAM, JJA, SON column 1, 2, 3, 4 respectively between 0-5 months lead time before the beginning of each season. a-d MAE between MME and GPCC. e-h MAE between MME and NMME CPC PRATE

Figure 6 shows the Normalized Root Mean Square Error (NRMSE). The result shows that the NRMSE increases after first lead time for all seasons studied. These results suggest that differences between prediction and observation may be larger as the model initialization period increases. On the other hand, analysis of the quality of MME rainfall forecasts shows that the performance of the forecasting system is better for the first month and from 3 to 5 months, measurements seem less good and the performance of the model remains relatively constant. This follows results of literature review, which indicate good performance of seasonal rainfall forecasts up to a few weeks or even a few months before the beginning of the seasons (Crochemore et al 2016; Tanessong et al 2020). 

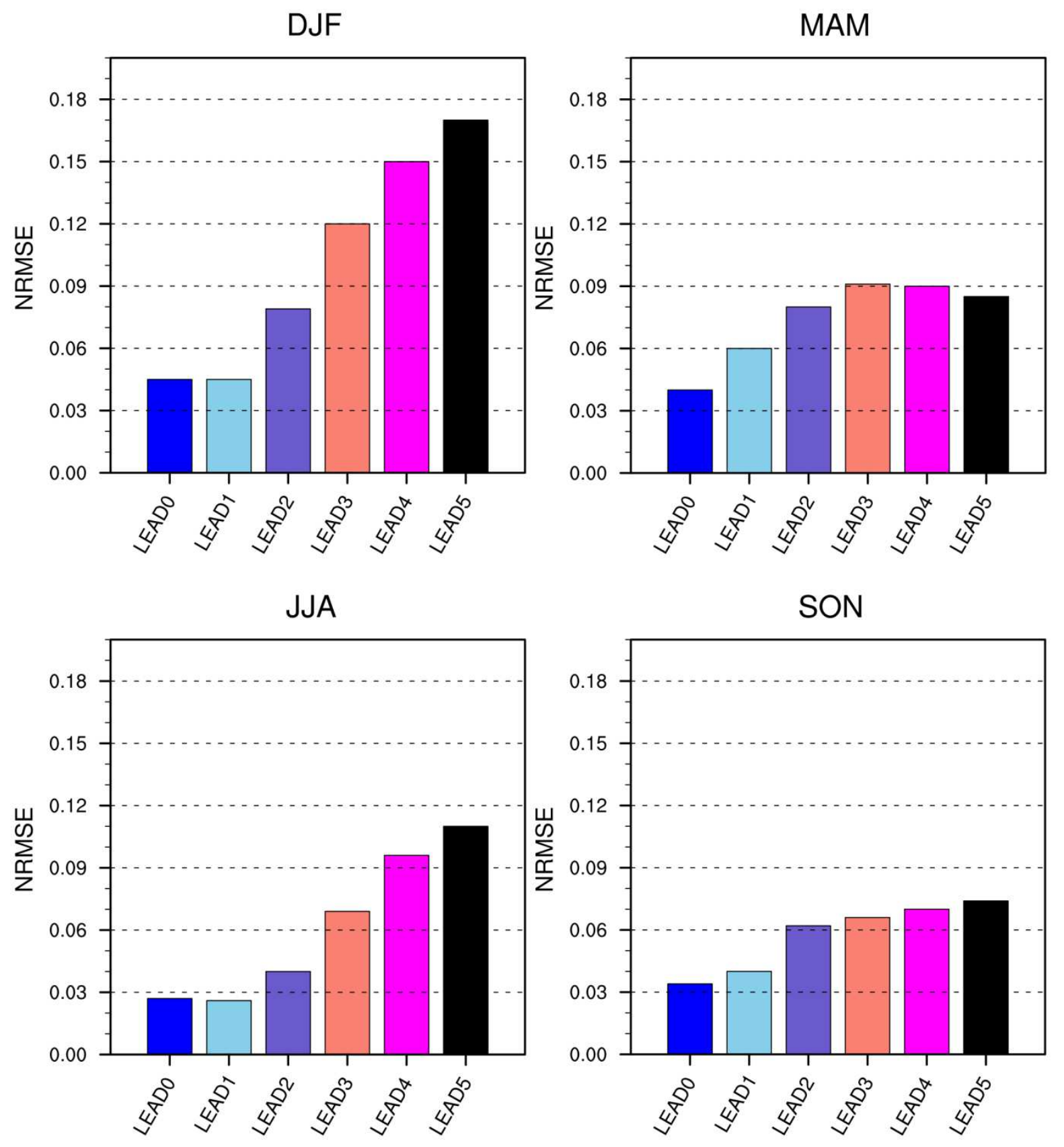

Fig. 6 Normalized Root Mean Square Error (NRMSE) between MME and the mean observation (GPCC and NMME CPC PRATE). 0-5 months lead time before the start for each season 
The Taylor diagram (Taylor et al 2001) used in this paper presents the spatio-temporal similarity or dissimilarity between MME and a reference observation GPCC Figure 7. The black lines relative to the radial axis show correlation coefficient (R) between MME and GPCC observation. The black dotted semi-circles show spatial standard deviation between MME and GPCC. The results show that $R$ values in the graph over 0 to 2 months lead time, forecast periods have a correlation coefficient well above the mean, between 0.6 and 0.95 for JJA season, around 0.49 to 0.92 for MAM and around 0.69 to 0.96 for DJF and SON seasons. On the other hand, lead 3 to lead 5 values for all seasons show a low correlation coefficient. Standard deviations are in the range of 1 to 1.50 for DJF, 1.10 to 1.26 for MAM seasons, 0.5 to 0.98 for JJA and 0.75 to 1.47 for SON season. These results over Taylor diagram shows that the link between MME and GPCC depends on season and especially on the month of the initialization of the model (Mo et al 2015; Shukla et al 2016; Givati et al 2017).

DJF

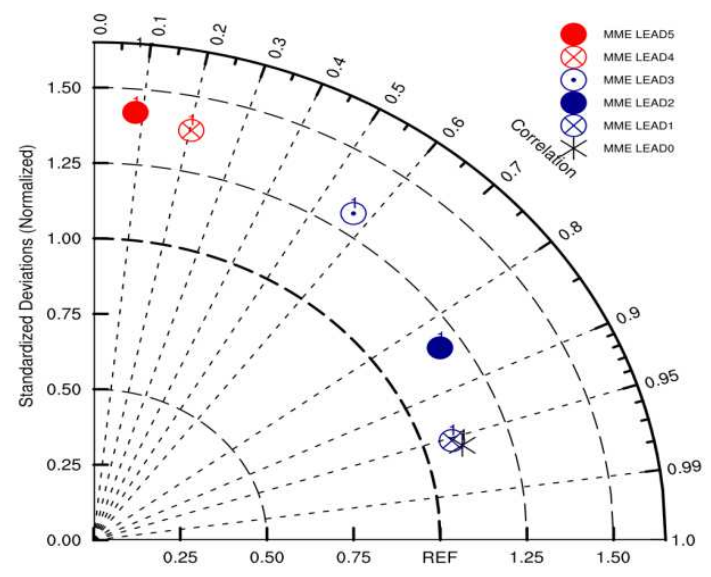

JJA

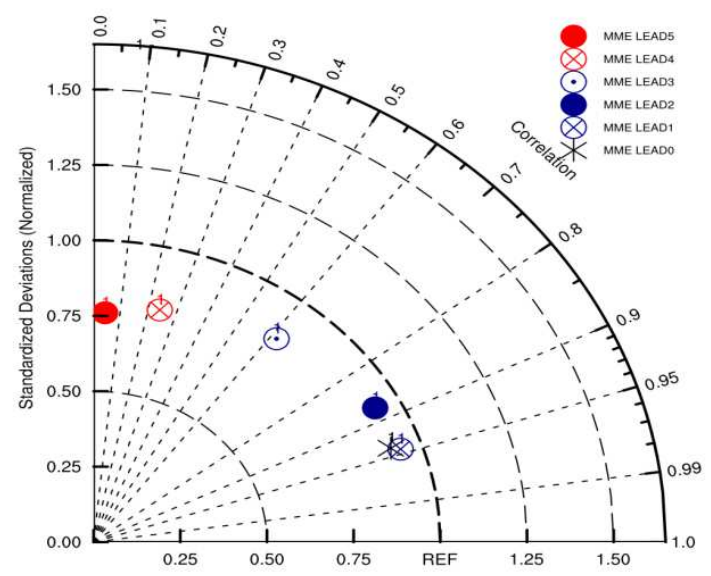

MAM

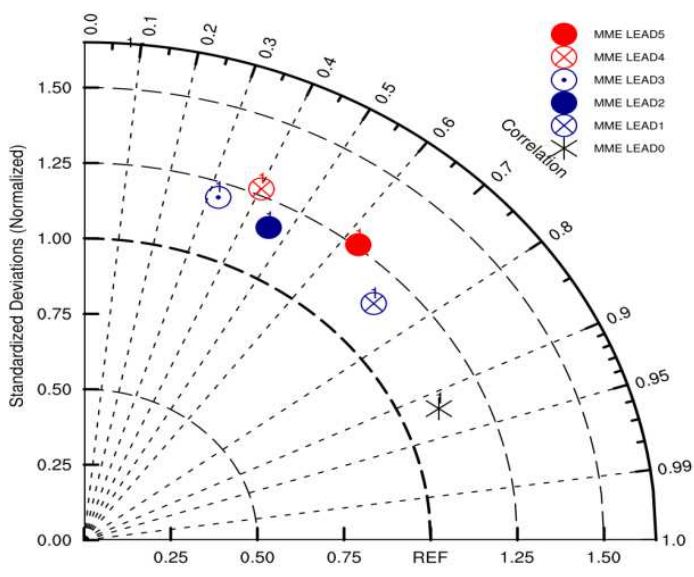

SON

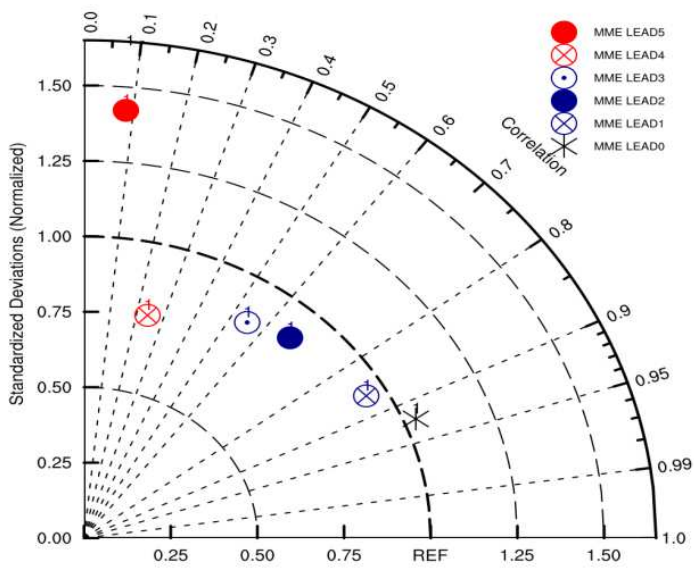

Fig. 7 Taylor diagram presenting the correlation $(R)$ and the standard deviation between the MME (1982- 2009) namely (MME lead0, MME lead1, MME lead2, MME lead3, MME lead4 and MME lead5), with GPCC the observation of reference 


\subsection{Categorical skill analysis}

Figure 8 represents the Probability of Detection (POD $\ \%$ ), the False Alarms (FAR $\backslash \%$ ), and the Correct percentage ( $\mathrm{PC} \backslash \%)$ of all seasons. The results suggest that above normal and below normal of the seasons DJF, MAM, JJA, SON studied have a very low $2 \backslash \%$ to $20 \backslash \%$ to low $20 \backslash \%$ to $40 \backslash \%$ PODs (Fig. 8a, b, c, d) red color and blue color. However a low probability in no way indicates that it will be sunny. It means that the probability of raining is low in CA for seasons above and below normal. During normal seasons, MME have reasonable POD greater than 50 \%. The values are between $581 \%$ and $61 \backslash \%$ for DJF and MAM seasons (Fig. 8a, b) green color. In JJA and SON (Fig. 8c, d) green color, the models seem to be more calibrated with large POD around $79 \backslash \%$ to $80 \nmid \%$, and $60 \backslash \%$ to $80 \backslash \%$ respectively. The False Alarm (FAR \%) shows values greater than $50 \backslash \%$ for all below normal seasons (Fig. 8e, f, j, h) blue color. These values reach the maximum percentage of $981 \%$ for the DJF season at lead 5, 83\\% in MAM season at lead 3, around $82 \ \%$ at lead 2 in JJA, and around $981 \%$ at lead 5 in SON season. The seasons above normal (Fig. 8e, f) red color, show FAR values above $60 \backslash \%$ for the DJF and MAM seasons. These values reach a maximum around $97 \backslash \%$ at lead 5 in DJF and around $95 \downarrow \%$ to lead 1 and lead 2. The JJA and SON seasons show FAR values around 39 $\backslash \%$ to $40 \backslash \%$ (Fig. 8 j, h) red color, lead 0 and lead 1 . From 2-5 months lead time the values are greater than $55 \backslash \%$. The important point to emphasize is the link between POD and FAR. When the POD of MME is low, FAR are higher in all seasons studied. In addition the FAR and POD values depend on the lead time and seasons of each category. (Fig. 8i, g, k, l) shows the correct percentage (PC $\backslash \%$ ) for the 4 seasons. The correct percentage is used to assess the confidence that can be placed in the forecast for each season. The results indicate that the PC values are between $39 \backslash \%$ and $60 \downarrow \%$ for MAM, DJF and SON. The JJA season presents the values between $41 \downarrow \%$ and $61 \downarrow \%$. However, since the data used to calculate the correct percentage only covers a 28 -year period, the threshold for being statistically significant is closer to $401 \%$ (Kharin et al 2001). These results show that the confidence level of each period is close to or greater than the defined threshold. It follows that the skill of forecasting varies with the seasons and with the initialization time (Mo et al 2015). After calculating different POD, FAR, and PC, it is important to observe the Critical Success Index (CSI), frequently used to verify the accuracy of predictions. Figure 9 shows the CSI for the normal, above and below normal seasons. The results indicate that the DJF seasons below and above normal, MAM above normal, JJA below normal and SON below normal have values less than 0.21 justifying that during these seasons less than $50 \backslash \%$ precipitation was well predicted by the MME. The CSI values for the DJF, MAM, JJA and SON seasons are higher compared to the season below and above normal. This result suggests that during normal seasons, just over half of the rainfall was correctly predicted by MME with an above-average percentage. 

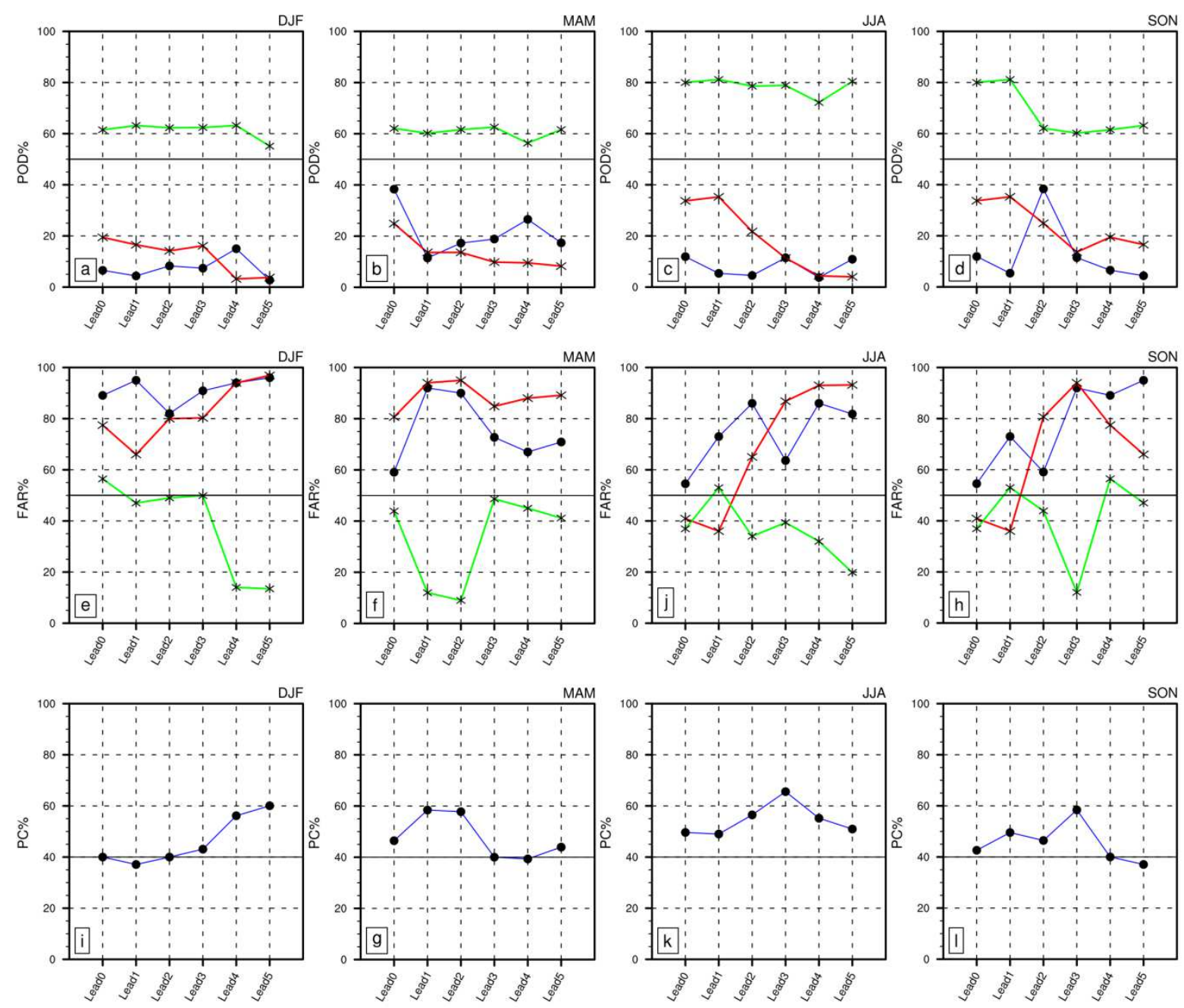

Fig. 8 Diagram representing Probability Of Detection (POD $\backslash \%$ ), False Alarm (FAR $\$ ) and Correct Percentage (PC $\%$ ) of MME rainfall for each season DJF, MAM, JJA, SON. a-d POD (above normal, below normal and normal) with green color represents the normal season, the blue color represents the below normal season and the red color represents the above normal season. e-h FAR (above normal, below normal and normal). The green color represents the normal season, the blue color represents the season below normal and the red color represents the season above normal. i-l PC for each season DJF, MAM, JJA, SON 

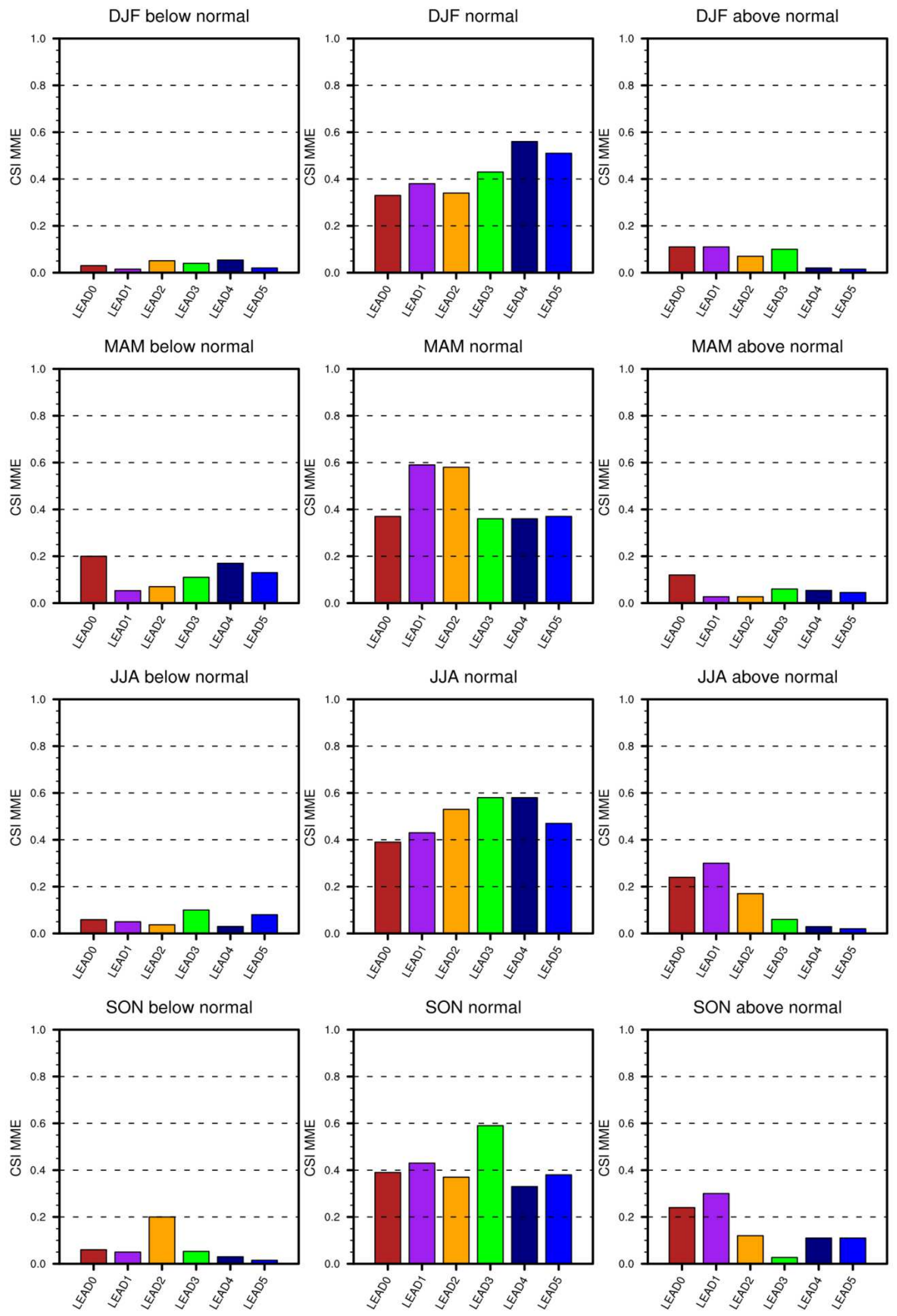

Fig.9 MME Critical Success Index (CSI), first-line DJF (below normal, above normal and normal). Second line MAM (below normal, above normal and normal). Third line JJA (below normal, above normal and normal). Fourth line SON (below normal, above normal and normal) 


\section{CONCLUSION}

The main objective of this study was to evaluate the skill of the North American Multi-Model Ensemble (NMME) in Central Africa (CA). The study was realized over 4 seasons: December to February (DJF), March to May (MAM), June to August (JJA), and September to November (SON). Deterministic and categorical scores calculated 1 to 5 months lead times before the beginning of the seasons were used, focusing on rainfall variables. This study was carried out in link with GPCC and NMME-CPC satellite rainfall observation data over the period 1982-2009 in the CA. The models represent the unimodal and bimodal structure of rainfall in the region. The NMME Multi-model Ensemble Mean (MME) reproduces the spatial structure of the two observations over CA with a remarkable bias between lead 3 and lead 5. These important biases require correction before use in certain fields of application for instance, hydrology. Taylor diagram shows correlations greater than 0.72 for the 4 seasons between lead 0 and lead 1 and shows low values as lead time increases. It follows that Probabilities of Detection (POD) and the Critical Success Index (CSI) of the normal seasons are high and remain very low for the above and below normal seasons. The interest of such a study allows the possibility to make early warnings against abnormal hydro meteorological events in the region. Also it could help farmers to make important choices concerning qualities of seeds to be cultivated according to the rhythm of the future season. This study will also allow forecasters and decision-makers (or government) to demand better consideration of all the uncertainties linked to natural phenomena. Thus, it was observed that several results obtained within this framework are in agreement with those present in the literature review over CA. Following these results, it will be desirable to continue the analysis within the framework of the calculation of new scores, used more within the framework of ensemble forecasting.

\section{Acknowledgments}

The authors would like to express a sincere gratitude to the German Federal Ministry for Education through the German Academic Exchange Service (DAAD) for supporting this research. We also thank Centre d'excellence d'Afrique en Science Mathématiques, Informatique et Applications (IMSP/CEA-SMIA) for internet connection at the institute. We sincerely thank the modeling groups and research centers, namely (Center for Ocean-Land-Atmosphere Studies (COLA), University of Miami, Geophysical Fluid Dynamics Laboratory (GFDL), IRI, NASA, NCAR, and NCEP) for the creation, regular updating and provision of their NMME models. For this article, the data from the forecast NMME are downloaded at the following link https://iridl.ldeo.columbia.edu/ 


\section{Funding information}

The dissemination of NMME data is supported by the National Oceanic and Atmospheric Administration (NOAA), the National Science Foundation (NSF), the National Aeronautics and Space Administration (NASA) and the Department of United States Energy (DOE).

\section{Conflict of interest, code available of data, materiel, ethics approval, consent to participate, consent for publication}

The authors have no conflicts of interest to declare for the content of this article. The authors have no conflicts in the financial or material interests used in this article. This research was funded by DAAD. The manuscript is approved by all the authors and can follow publication procedures. All authors have correctly contributed. The programming languages used is NCAR Command Language (NCL) and Climate Data Operators (CDO). For this article, the data from the forecast NMME are downloaded at the following link https://iridl.ldeo.columbia.edu/

\section{References}

Adler R, Sapiano M, Huffman G, Bolvin D, Gu G, Wang J, Nelkin E, Xie E, Chiu L, Ferraro R, et al (2016) The new version 2.3 of the Global Precipitation Climatology Project (GPCP) monthly analysis product. University of Maryland, April 2016:1072-1084

Becker A, Finger P, Meyer-Christoffer A, Rudolf B, Schamm K, Schneider U, and Ziese M (2013) A description of the global land-surface precipitation data products of the Global Precipitation Climatology Centre with sample applications including centennial (trend) analysis from 1901-present: Earth System Science Data 5(1):71--99

Camberlin P, Janicot S, Poccard I, (2001) Role of inertial instability in the West African monsoon jump. International Journal of Climatology: A Journal of the Royal Meteorological Society 21(8):973--1005

Coppola E, Giorgi F, Raffaele F, Fuentes-Franco R, Giuliani G, LLopart-Pereira M, Mamgain A, Mariotti L, Diro GT, Torma C (2014) Present and future climatologies in the phase i crema experiment. Clim Chang 125(1):23-38

Crochemore L and, Ramos M.-H, Pappenberger F (2016) Bias correcting precipitation forecasts to improve the skill of seasonal streamflow forecasts. Hydrology and Earth System Sciences 20(9):3601--3618 
DeWitt DG (2005) Retrospective forecasts of interannual sea surface temperature anomalies from 1982 to present using a directly coupled atmosphere--ocean general circulation model. Monthly weather review 133(10):2972--2995

Dosio A, Panitz HJ, Schubert-Frisius M, L uthi D (2015) Dynamical downscaling of CMIP5 global circulation models over CORDEX-Africa with COSMO-CLM: evaluation over the present climate and analysis of the added value. Climate Dynamics 44(9):2637--2661

Fotso-Nguemo TC, Vondou DA, Tchawoua C, Haensler A (2017) Assessment of simulated rainfall and temperature from the regional climate model REMO and future changes over Central Africa. Climate Dynamics 48(11-12):3685--3705

Fotso-Nguemo TC, Chamani R, Yepdo ZD, Sonkoué D, Matsaguim CN, Vondou DA, Tanessong RS(2018) Projected trends of extreme rainfall events from CMIP5 models over Central Africa. Atmospheric Science letters (19)2:e803

Galvin, JFP (2008) the weather and climate of the tropics: Part 6--Monsoons. Weather (63)5:129--137

Givati, Amir H, Mashor L, Yoav Paz, Dror C, Itzhak B, Emily (2017) The advantage of using international multimodel ensemble for seasonal precipitation forecast over Israel. Advances in Meteorology 2017(2017)

Haensler A, Saeed F, D Jacob (2013) Assessing the robustness of projected precipitation changes over central Africa on the basis of a multitude of global and regional climate projections. Climatic Change 121(2):349-363

Hagedorn R, Doblas-Reyes FJ, Palmer TN (2005) The rationale behind the success of multi-model ensembles in seasonal forecasting-I. Basic concept. Journal of Tellus A: Dynamic Meteorology and Oceanography 57(3):219-233

Hamatan M, Mahe G, Servat É, Paturel J-E, Amani A(2004) Synthèse et évaluation des prévisions saisonnières en Afrique de l'Ouest: Sécheresse 15(3):279--286

Jackson B, Nicholson SE, Klotter D (2009) Mesoscale convective systems over western equatorial Africa and their relationship to large-scale circulation. Monthly Weather Review 137(4):1272--1294

Jenkins GS, Gaye ATM, Sylla B (2005) Late 20th century attribution of drying trends in the Sahel from the Regional Climate Model (RegCM3). Geophysical Research Letters 32(22) Wiley Online Library (2005)

Kharin W, Zwiers FW, Gagnon N (2001) Skill assessment of seasonal hindcasts as a function of the ensemble size Climate Dynamics 17(11):835--843 
Kirtman BP, Min D, Infanti JM, Kinter III JL , Paolino DA, Zhang Q, Van Den Dool H, Saha S Mendez MP, Becker E, et al (2014) The North American multimodel ensemble: phase-1 seasonal-to-interannual prediction; phase-2 toward developing intraseasonal prediction: Bulletin of the American Meteorological Society 95(4):585--601

Kug JS, Lee JY, Kang IS, Wang B, Chung-Kyu P(2008) Optimal multi-model ensemble method in seasonal climate prediction. Asia-Pacific Atmospheric Sciences 44(3): 259--267

Liu M, Huang Y, Ma Z, Jin Z, Xingyu L, Wang Haikun, Yang L, Wang J, Jantunen M, Jun B, et al (2017) Spatial and temporal trends in the mortalityburden of air pollution in China: 2004--2012. Environment international 98:75--81

Marchandise Arthur (2007) Modélisation hydrologique distribuée et sur le Gardon d'Anduze; étude comparative de différents modèles pluie-débit, extrapolation de la normale à l'extrême et tests d'hypothèses sur les processus hydrologiques. Université de Montpellier II, Montpellier (2007)

Mason SJ, Goddard L (2001) Probabilistic precipitation anomalies associated with ENSO. Bulletin of the American Meteorological Society82 (4):619--638

Mo KC, Lyon B (2015) Global meteorological drought prediction using the North American multi-model ensemble. Journal of Hydrometeorology 16(3):1409--1424

Nicholson SE, Grist JP (2003) the seasonal evolution of the atmospheric circulation over west Africa and equatorial Africa. Journal of climate 16(7):1013-1030.

Nicholson SE (2018) The ITCZ and the seasonal cycle over equatorial Africa. Bulletin of the American Meteorological Society 99(2):337-348

Nikulin G, Jones C, Giorgi F, Asrar G, Büchner M, Cerezo-Mota R, Christensen OB, Déqué M, Fernandez J, Hänsler A et al (2012) precipitation climatology in an ensemble of CORDEX-Africa regional climate simulations. Journal of climate 25(18):6057--6078

Palmer MA, Reidy Liermann CA, Nilsson C, Flörke M, Alcamo J, Lake PS, Bond N, (2008) Climate change and the world's river basins: anticipating management options. Frontiers in Ecology and the Environment6 (2):81--89

Roncoli C, Jost C, Kirshen P, Sanon M, Ingram KT, Woodin M Somé, Léopold, Ouattara F, Sanfo B J, Sia C and al (2009) from accessing to assessing forecasts: an end-to-end study of participatory climate forecast dissemination in Burkina Faso (West Africa). Climatic Change 92(3-4):433 
Schneider AFPMCARBZM Udo; Becker (2011) GPCC full data reanalysis version 7.0 at 0.5 : monthly landsurface precipitation from rain-gauges built on GTS-based and historic data. (GPCC), DWD 112

Shrivastava S, Kar SC, Sharma AR (2019) Probabilistic predictions of the Indian monsoon rainfall in belownormal category using NMME global model products.Theoretical and Applied Climatology137 (1-2):623—636

Shukla S, Jason R, Hoell A, Funk C, Robertson C Franklin, Kirtman B (2016) Assessing north american multimodel ensemble 605 (nmme) seasonal forecast skill to assist in the early warning of anomalous hydrometeorological events over East Africa. Climate Dynamics 53(12):7411—7427

Slater L J, Villarini G, Bradley A A (2017) Weighting of NMME temperature and precipitation forecasts across Europe. Journal of Hydrology 552(555):646—659

Stanski H L Wilson, Laurence J, Burrows W (1989) Survey of common verification methods in meteorology in meteorology. World weather watch tech. rep. 8: Meteorological Organization Geneva, Switzerland

Sultan B, Janicot S (2013) The West African monsoon dynamics. Part II: The "pre onset" and "onset" of the summer monsoon. Journal of climate 16(21):3407-3427

Tamoffo AT, Vondou DA, Pokam WM, Haensler A, Yepdo ZD, Fotso-Nguemo TC, Tchotchou LAD, Nouayou R (2019) Daily characteristics of central African rainfall in the REMO model. Theoretical and Applied Climatology137 (3-4):2351-2368

Tanessong RS, Fotso-Nguemo TC, Mbienda AK, Guenang G, Sandjon AT, Kaissassou S, Vondou AD (2020) Assessing Climate-system Historical Forecast Project (CHFP) seasonal forecast skill over Central Africa. Theoretical and Applied Climatology 1-12

Taylor Karl E (2001) Summarizing multiple aspects of model performance in a single diagram. Journal of Geophysical Research: Atmospheres106 (D1):7183-7192

Thober S, Kumar R, Sheffield J, Mai J, Schäfer D, Samaniego L (2015) Seasonal soil moisture drought prediction over Europe using the North American Multi-Model Ensemble (NMME): Journal of Hydrometeorology16(6):2329-2344

Tippett M, Barnston K AG, Robertson AW (2007) Estimation of seasonal precipitation tercile-based categorical probabilities from ensembles. Journal of Climate 20(10):2210-2228

Vondou DA, Nzeukou A, Lenouo A, Kamga FM (2010a) Seasonal variations in the diurnal patterns of convection in Cameroon--Nigeria and their neighboring areas: Atmospheric letters 11(4)(290--300) 
Wang B, Ding Q, Fu X, Kang I-S, Jin K, Shukla J, Doblas-Reyes F (2005) Fundamental challenge in simulation and prediction of summer monsoon: Geophysical Research Letters 32(15)

Wu R, Hu Z-Z, Kirtman bp (2003) Evolution of ENSO-related rainfall anomalies in East Asia. American Meteorological Society 16(22):3742-3758

Yuan X, Wood EF, Luo L, Pan M (2011) A first look at Climate Forecast System version 2 (CFSv2) for hydrological seasonal prediction: Geophysical research letters 38(13)

Zhang L, Xiaoliu Y (2018) Applying a multi-model ensemble method for long-term runoff prediction under climate change scenarios for the Yellow River Basin, China. Journal of Water 10(3):301

Zhao T, Zhang Y, Chen X (2019) Predictive performance of NMME seasonal forecasts of global precipitation: A spatial-temporal perspective. Journal of Hydrology 570:17--25 
Figures

\section{Central Africa Topography}

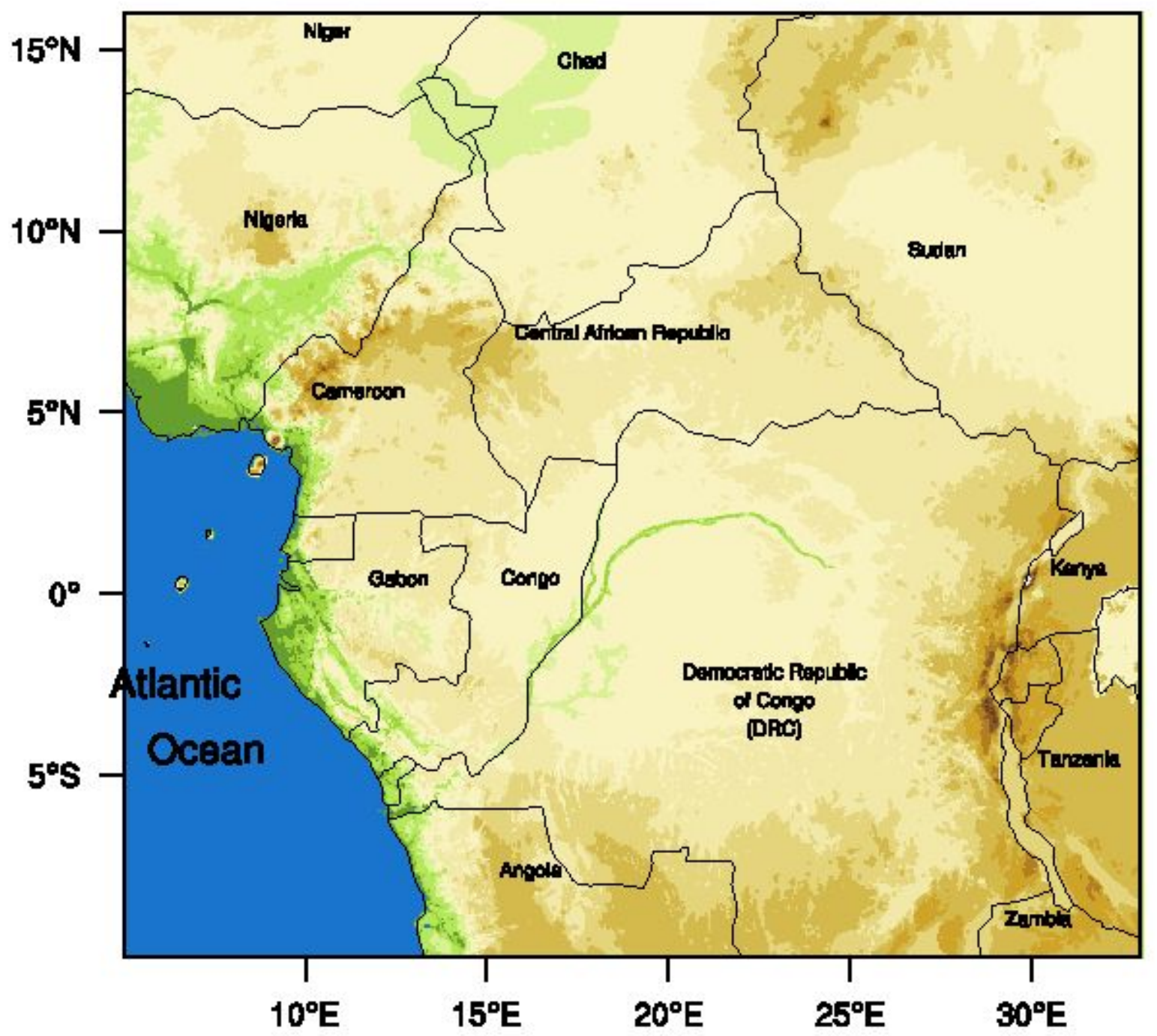

(mi)

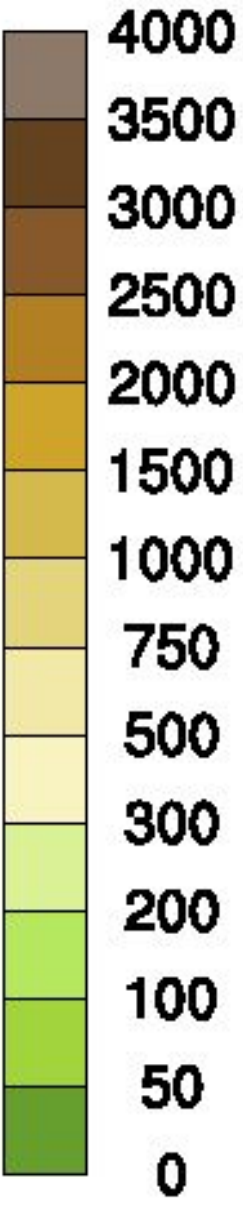

Figure 1

Study area located between the latitudes $-10^{\circ}$ to $16^{\circ}$ and longitudes $5^{\circ}$ to $33^{\circ}$ 

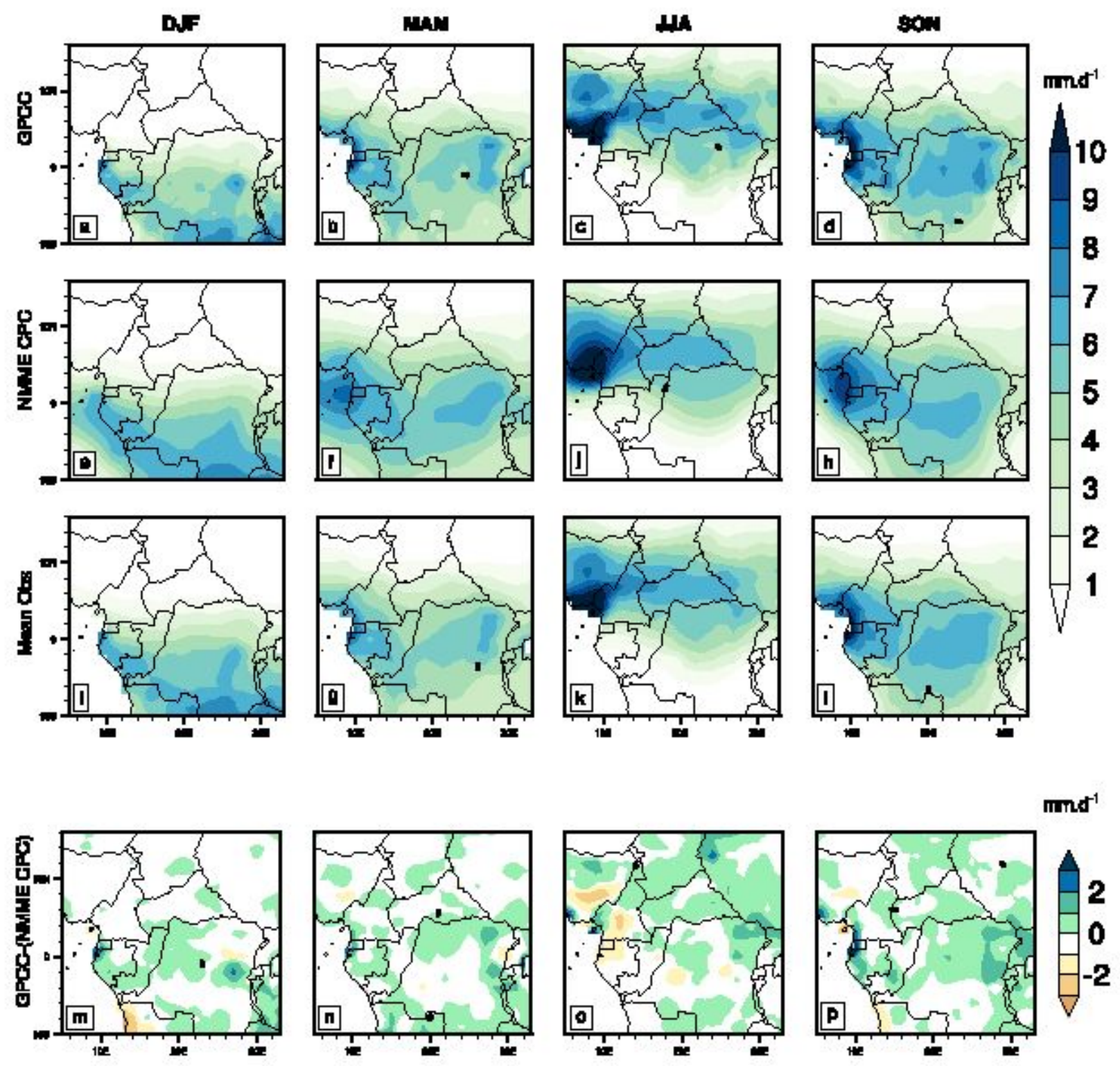

Figure 2

Rainfall climatologies observed (1982-2009), a-d GPCC. e-h NMME CPC PRATE. i-l means observation. m$p$ difference between GPCC and NMME CPC PRATE. For DJF column 1, MAM column 2, JJA column 3 and SON column 4 

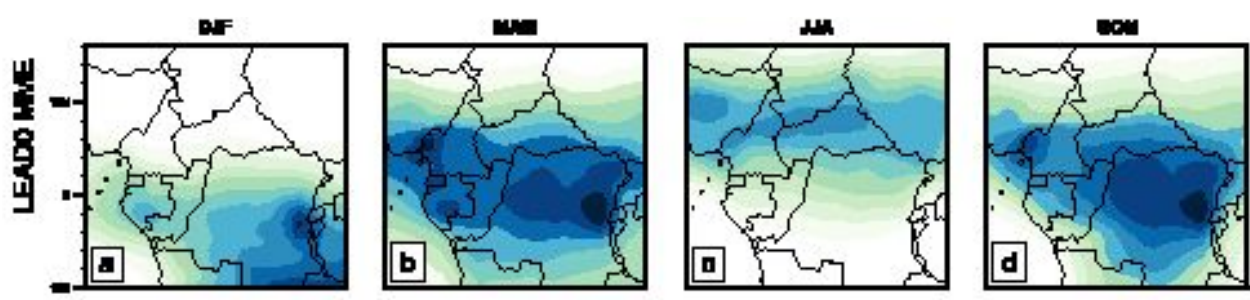

mmnt
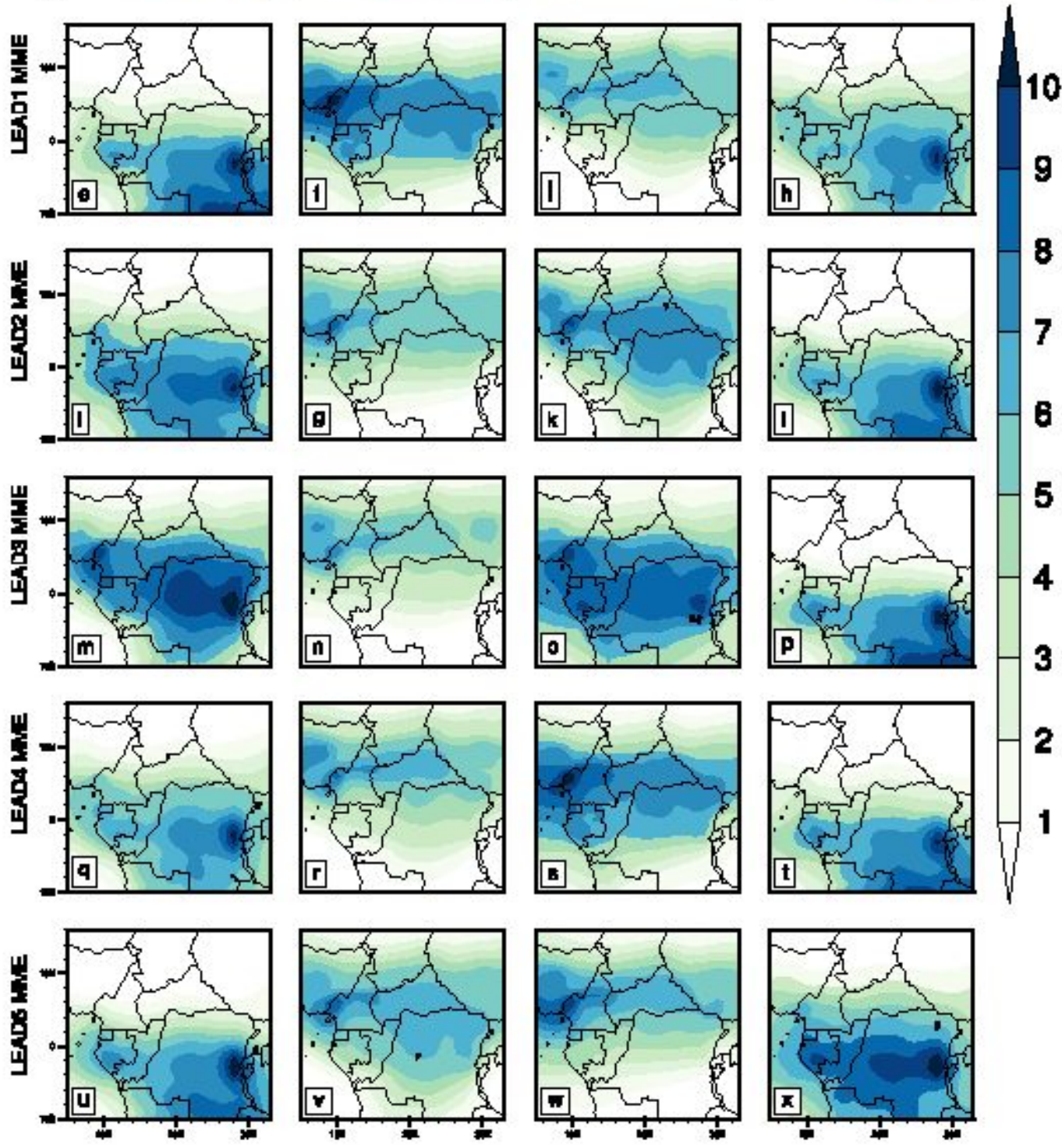

Figure 3

Seasonal forecast MME (1982-2009) rainfall ( $\mathrm{mm} /$ day). DJF column 1, MAM column 2, JJA column 3 and SON column 4.0 to 5 months lead time before the start of each season. a-d lead 0. e-h lead 1. i-l lead 2. m-p lead 3. q-t lead 4. u-x leads 5 

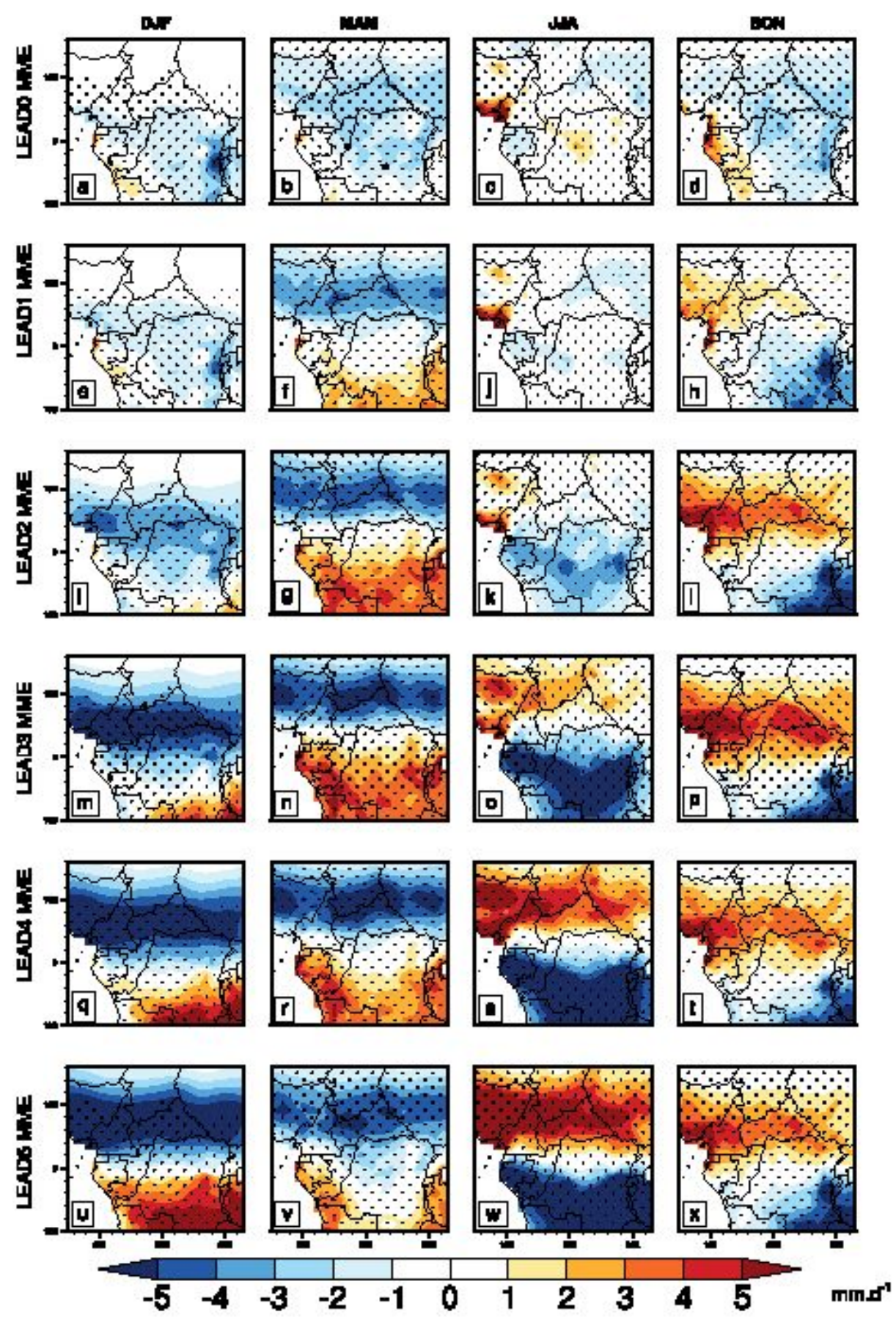

Figure 4

Spatial distribution (1982-2009) MME bias. DJF column 1, MAM column 2, JJA column 3 and SON column 4.0 to 5 months lead time before the start of each season. a-d lead 0. e-h lead 1. i-l lead 2. m-p lead 3. q-t lead 4. u-x lead 5. The small black dots represent the significance test carried out at 95\\% 

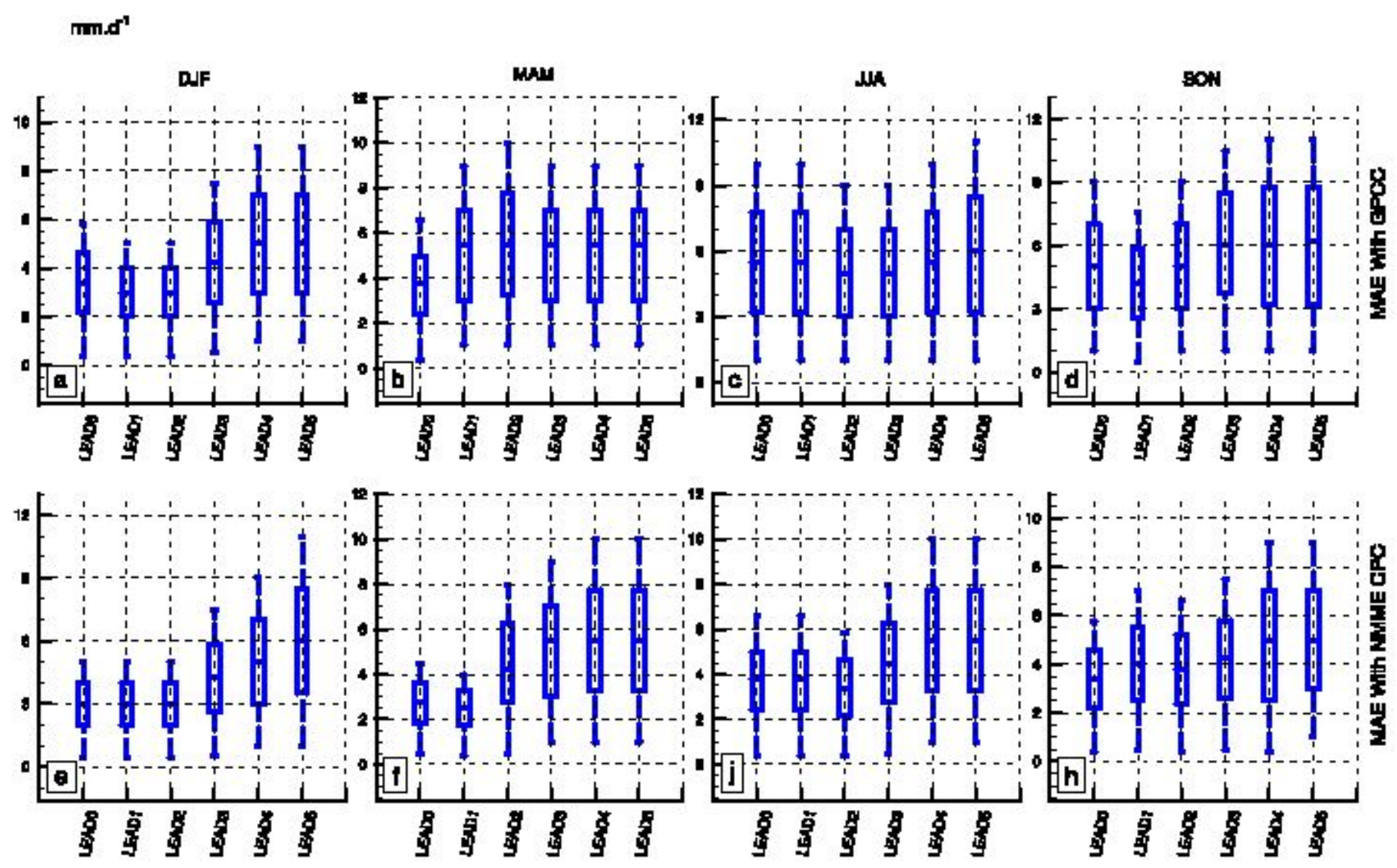

Figure 5

Box Plot representing the Mean Absolute Error (MAE) between the two observations GPCC and CPC NMME PRATE and the MME. For DJF, MAM, JJA, SON column 1, 2, 3, 4 respectively between 0-5 months lead time before the beginning of each season. a-d MAE between MME and GPCC. e-h MAE between MME and NMME CPC PRATE 

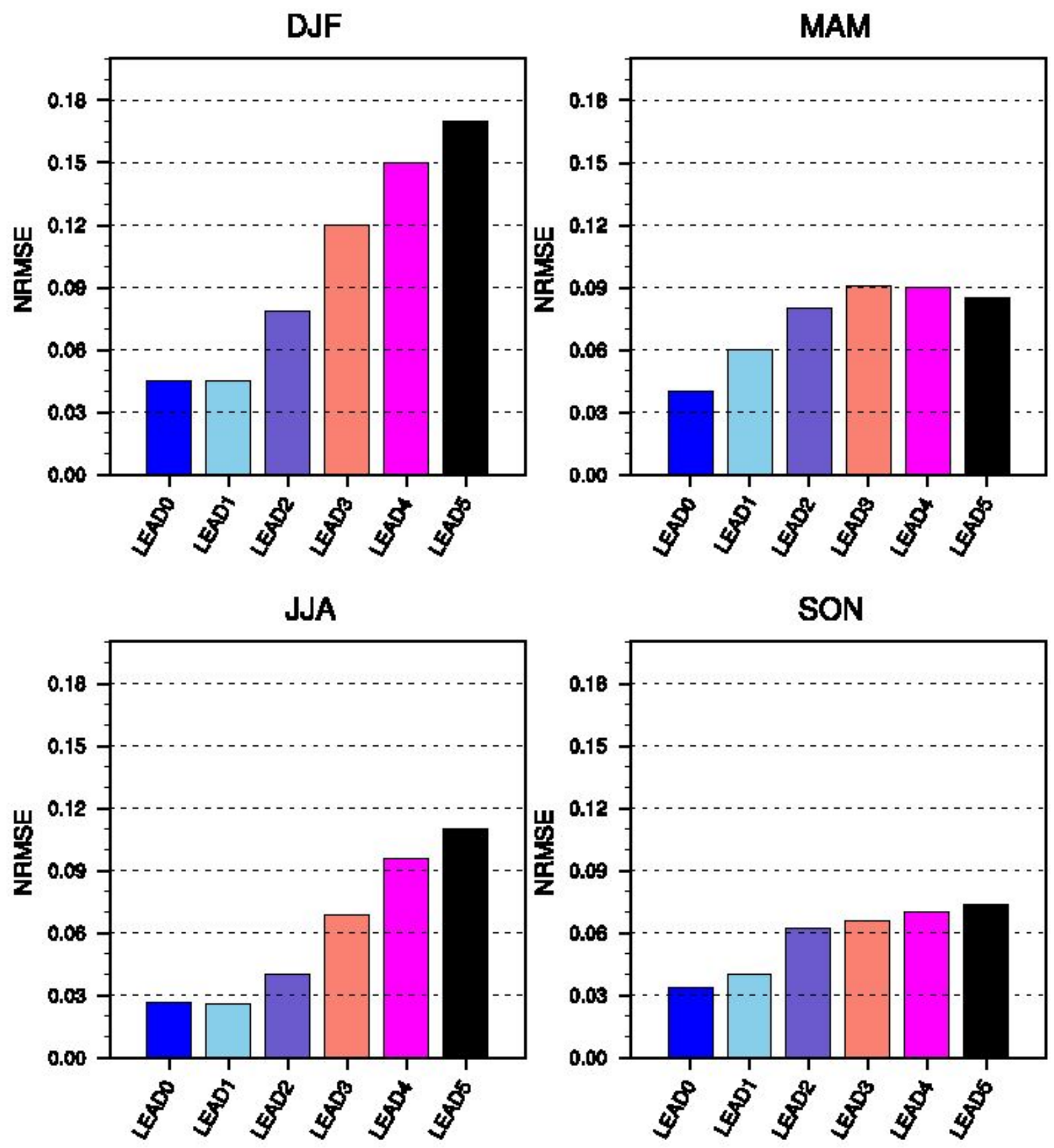

Figure 6

Normalized Root Mean Square Error (NRMSE) between MME and the mean observation (GPCC and NMME CPC PRATE). 0-5 months lead time before the start for each season 
DJF

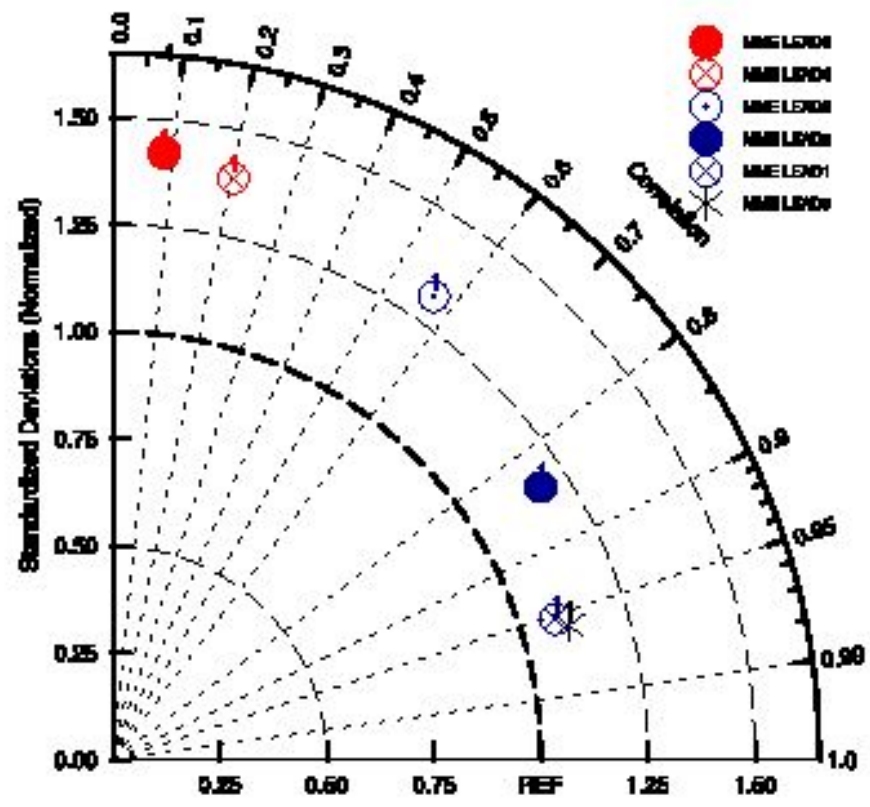

JJA

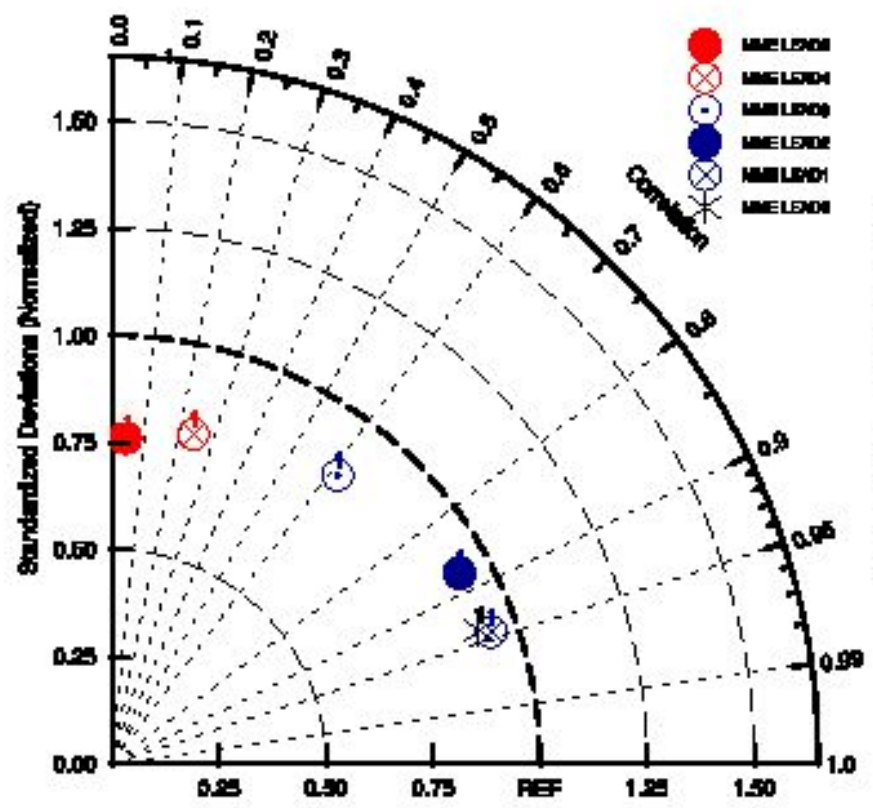

MAM

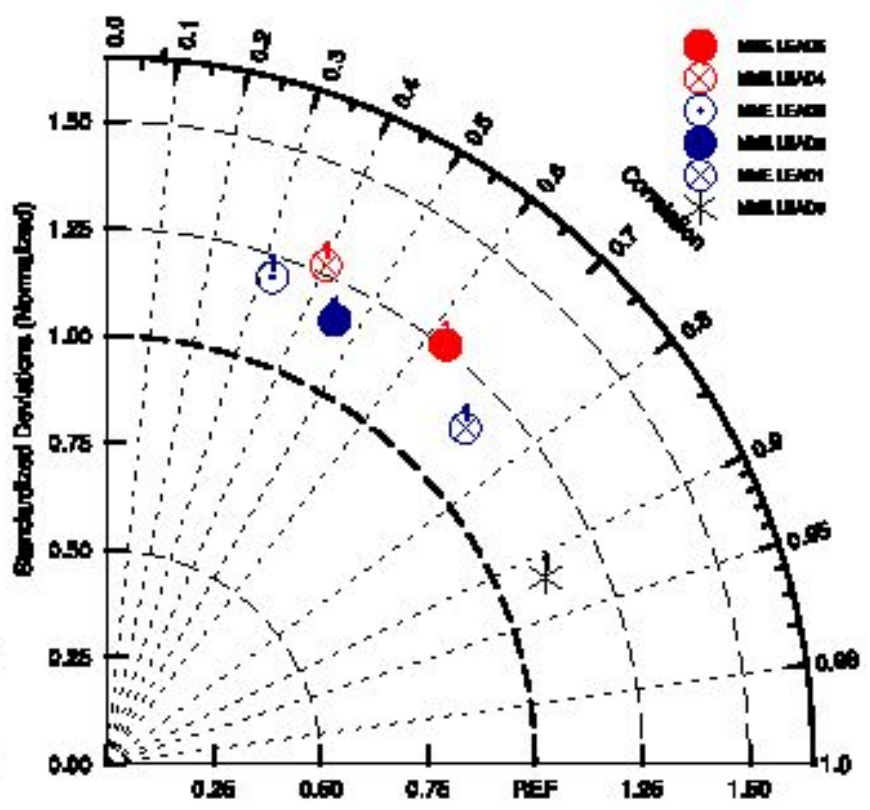

SON

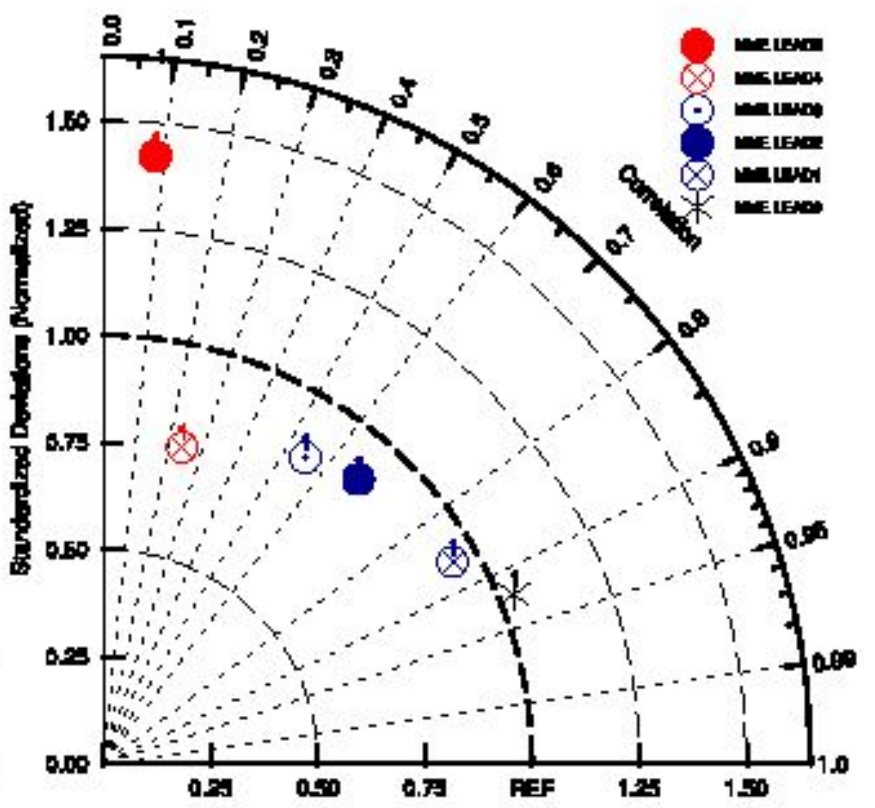

Figure 7

Taylor diagram presenting the correlation $(R)$ and the standard deviation between the MME (1982-2009) namely (MME lead0, MME lead1, MME lead2, MME lead3, MME lead4 and MME lead5), with GPCC the observation of reference 

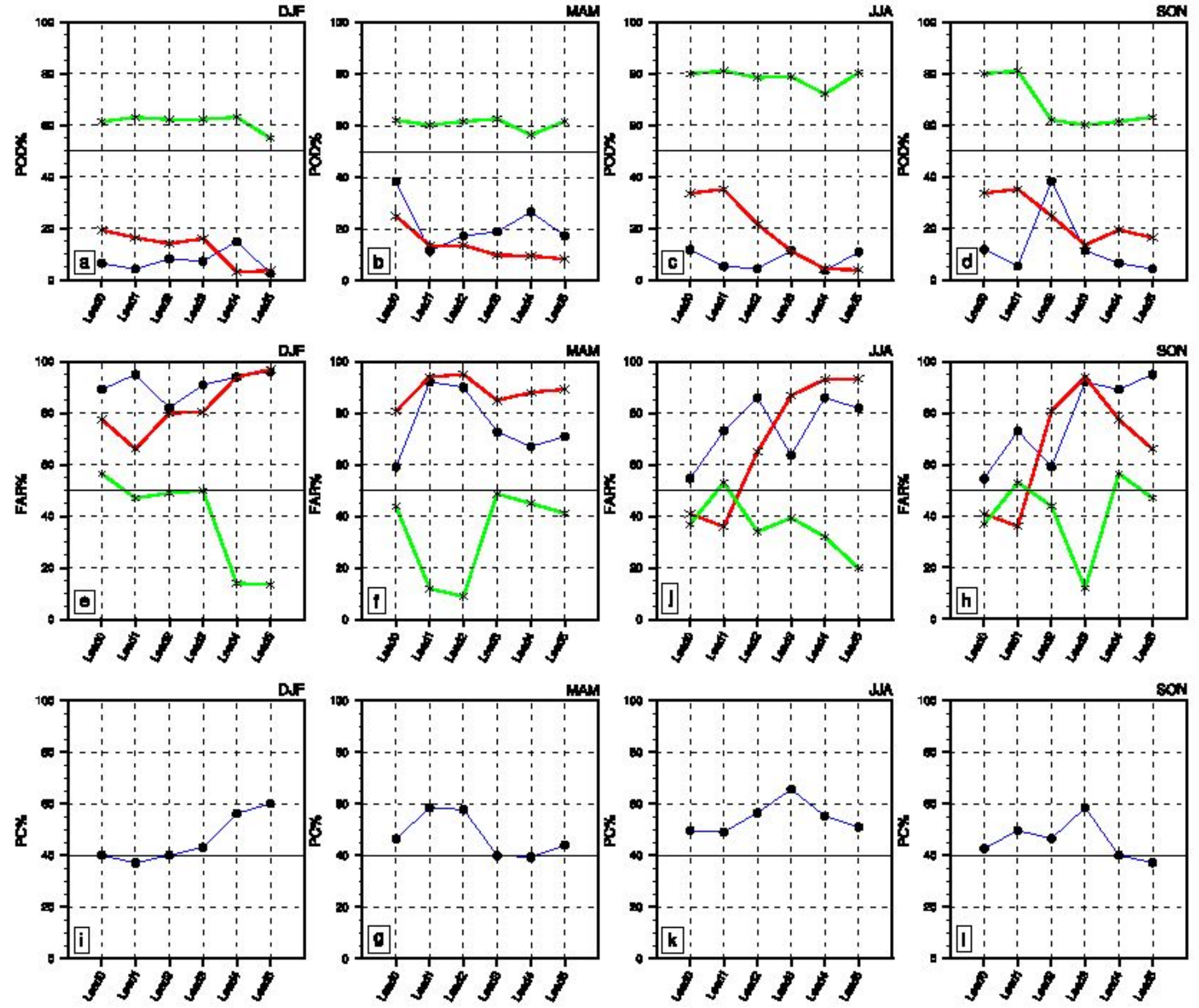

\section{Figure 8}

Diagram representing Probability Of Detection (POD $\backslash \%)$, False Alarm (FAR \%) and Correct Percentage (PCI\%) of MME rainfall for each season DJF, MAM, JJA, SON. a-d POD (above normal, below normal and normal) with green color represents the normal season, the blue color represents the below normal season and the red color represents the above normal season. e-h FAR (above normal, below normal and 
normal). The green color represents the normal season, the blue color represents the season below normal and the red color represents the season above normal. i-I PC for each season DJF, MAM, JJA, SON
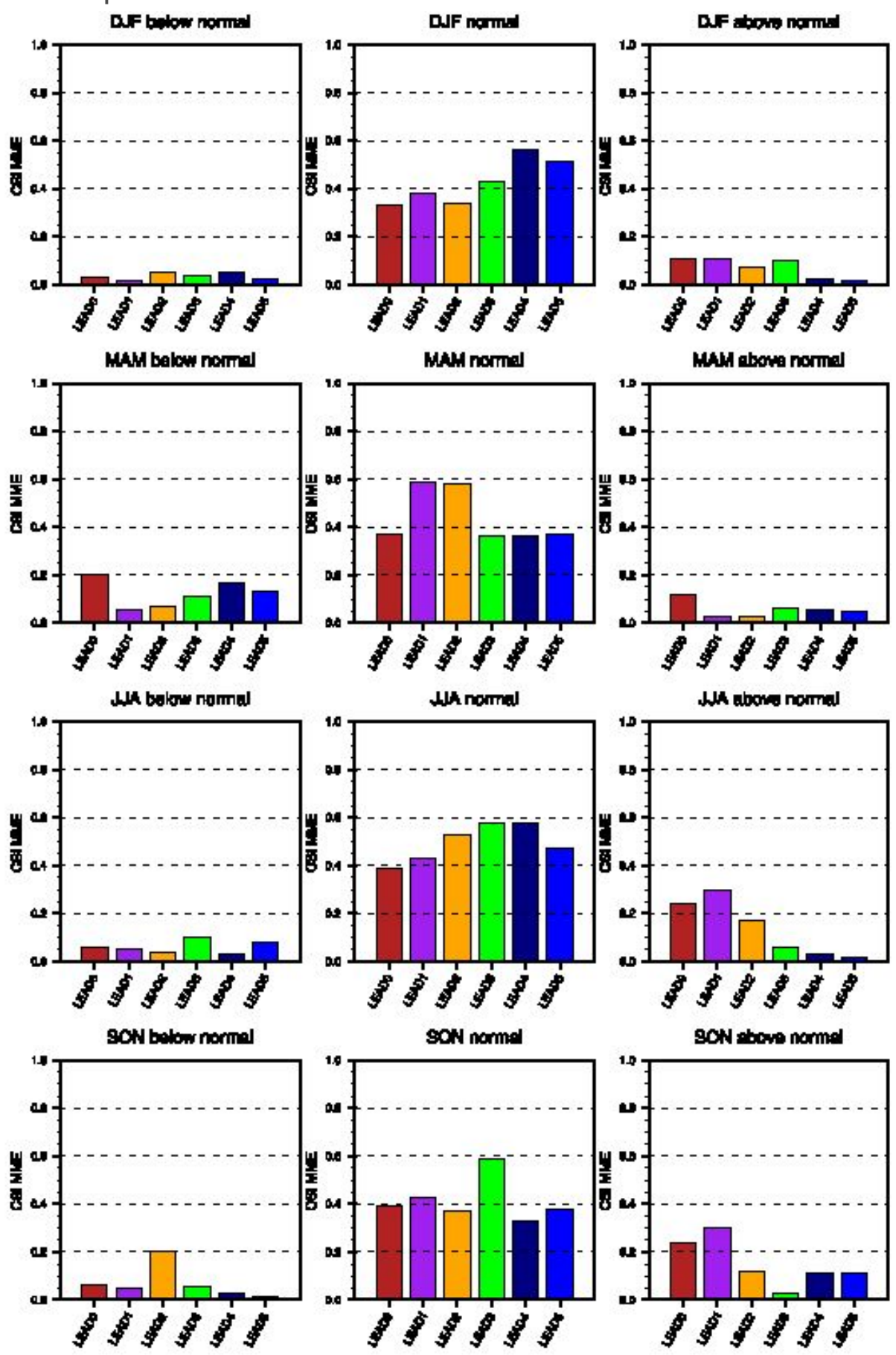

Figure 9

MME Critical Success Index (CSI), first-line DJF (below normal, above normal and normal). Second line MAM (below normal, above normal and normal). Third line JJA (below normal, above normal and normal). Fourth line SON (below normal, above normal and normal) 